\title{
A role for the Cdc7 kinase regulatory subunit Dbf4p in the formation of initiation-competent origins of replication
}

\author{
Philippe Pasero, ${ }^{1,3}$ Bernard P. Duncker, ${ }^{1}$ Etienne Schwob, ${ }^{2}$ and Susan M. Gasser ${ }^{1,4}$ \\ ${ }^{1}$ Swiss Institute for Experimental Cancer Research (ISREC), CH-1066 Epalinges/Lausanne, Switzerland; \\ ${ }^{2}$ Institute of Molecular Genetics, UMR 5535, Centre National de la Recherche Scientifique, F-34033 Montpellier, France
}

\begin{abstract}
Using a reconstituted DNA replication assay from yeast, we demonstrate that two kinase complexes are essential for the promotion of replication in vitro. An active Clb/Cdc28 kinase complex, or its vertebrate equivalent, is required in trans to stimulate initiation in $\mathrm{G}_{\mathbf{1}}$-phase nuclei, whereas the Dbf4/Cdc7 kinase complex must be provided by the template nuclei themselves. The regulatory subunit of Cdc7p, Dbf4p, accumulates during late $G_{1}$ phase, becomes chromatin associated prior to $\mathrm{Clb} / \mathrm{Cdc28}$ activation, and assumes a punctate pattern of localization that is similar to, and dependent on, the origin recognition complex (ORC). The association of Dbf4p with a detergent-insoluble chromatin fraction in $G_{1}$-phase nuclei requires ORC but not $\mathrm{Cdc} 6 \mathrm{p}$ or $\mathrm{Clb} / \mathrm{Cdc} 28$ kinase activity, and correlates with competence for initiation. We propose a model in which Dbf4p targets $C d c 7 p$ to the prereplication complex prior to the $G_{1} / S$ transition, by a pathway parallel to, but independent of, the Cdc6p-dependent recruitment of MCMs.
\end{abstract}

[Key Words: DNA replication; CDC28; CDC7; DBF4; S-phase-promoting factor]

Received March 1, 1999; revised version accepted June 28, 1999.

Replication of the eukaryotic genome is achieved by DNA synthesis at bidirectional forks that initiate at multiple sites along the chromosome (Coverley and Laskey 1994). The initiation event is generally believed to be regulated by a two-step mechanism. First, during the $\mathrm{G}_{1}$ phase of the cell cycle an origin-associated complex assembles, rendering nuclei competent for initiation. Then, at the $\mathrm{G}_{1} / \mathrm{S}$ transition, a diffusible S-phase-promoting factor (SPF) triggers the events of origin unwinding and subsequent DNA synthesis (Rao and Johnson 1970). In budding yeast, this assembly occurs at autonomous replication sequences (ARS), which bind the sixcomponent origin recognition complex (ORC; for review, see Newlon 1997). All ARS elements function as replication origins on plasmids, although some are either inactive or late firing in their native chromosomal context (Brewer et al. 1993), due to local chromatin structure or possibly subnuclear context (Raghuraman et al. 1997).

The prereplicative complex (pre-RC) is a prerequisite for origin-specific initiation and requires the binding of factors whose assembly is inhibited by high $\mathrm{Clb} / \mathrm{Cdc} 28$ activity (Diffley 1996; Piatti et al. 1996; Aparicio et al.

${ }^{3}$ Present address: Institute of Molecular Genetics (IGM), Unité Mixte de Recherche (UMR) 5535, Centre National de la Recherche Scientifique (CNRS), F-34033 Montpellier, France.

${ }^{4}$ Corresponding author.

E-MAIL sgasser@eliot.unil.ch; FAX 41216526933.
1997; Liang and Stillman 1997; Tanaka et al. 1997). Thus, even though ORC remains origin bound throughout the cell cycle (Diffley et al. 1994), other factors like Cdc6p (Piatti et al. 1995) and members of the MCM family (minichromosome maintenance, Hennessy et al. 1991; Yan et al. 1991) can be recruited only in $\mathrm{G}_{1}$. A change in the DNase I footprint of the pre-RC correlates with initiation of DNA replication, coincident with the loss of Cdc6p and MCMs from the complex (Diffley et al. 1994; Tanaka et al. 1997). Their rebinding cannot occur until the cell traverses mitosis and B-type cyclins are degraded (for review, see Dutta and Bell 1997; Newlon 1997). It is not known what components constitute the minimal functional pre-RC, nor is it clear what function is provided by Cdc45p, a factor that associates only after $\mathrm{Clb} / \mathrm{Cdk} 1$ activation (Zou and Stillman 1998). Nonetheless, it has been proposed that pre-RC assembly, coupled with a fluctuation of cyclin-dependent kinase activity, provides a means to restrict initiation to once-per-cell cycle (Diffley 1996).

In yeast, two kinases encoded by the genes CDC28 and CDC7, are essential for the $\mathrm{G}_{1} / \mathrm{S}$ transition (Hereford and Hartwell 1974; Hartwell 1976) and are the best candidates for providing SPF function. Cdc28p, the major cyclin-dependent kinase of yeast (Schwob and Nasmyth 1996; Jallepalli and Kelly 1997), associates with the Btype cyclins Clb5p and Clb6p at the end of $G_{1}$ phase (Schwob and Nasmyth 1993) and promotes the entry into 
$\mathrm{S}$ phase after the degradation of the $\mathrm{Clb} / \mathrm{Cdk}$ inhibitor Siclp (Schwob et al. 1994; Verma et al. 1997). Although Cdc28p interacts with several initiation factors and phosphorylates some of them in vitro (Jallepalli and Kelly 1997), it remains unresolved which, if any, of the pre-RC components is its critical substrate.

CDC7 encodes a $58-\mathrm{kD}$ serine/threonine kinase that is conserved in Schizosaccharomyces pombe, Xenopus, and human cells (Bahman et al. 1988; Hollingsworth and Sclafani 1990; Yoon and Campbell 1991; Masai et al. 1995; Jiang and Hunter 1997; Sato et al. 1997). Its activity, as measured on an artificial substrate, peaks at the $\mathrm{G}_{1} / \mathrm{S}$ transition (Jackson et al. 1993), although CDC7 mRNA and protein levels remain constant throughout the cell cycle (Sclafani et al. 1988; Jackson et al. 1993). Because Cdc7p kinase activity depends on interaction with a regulatory subunit called Dbf4p (Dumbbell-forming), whose transcription is under cell cycle control (Chapman and Johnston 1989), it has been proposed that the fluctuation of Dbf4p levels might result in the Sphase-specific activation of the kinase (Kitada et al. 1992; Jackson et al. 1993). In addition, Cdc7p is a Cdc28p target in vitro, although the physiological role of this phosphorylation is unclear (Yoon et al. 1993; Sclafani and Jackson 1994).

CDC7-deficient strains arrest immediately after $\mathrm{Clb} /$ Cdc28 activation and before the initiation of DNA replication (Hereford and Hartwell 1974; Hartwell 1976). However, two studies have recently challenged the original proposal that Cdc7p acts as a general regulator of the $\mathrm{G}_{1} / \mathrm{S}$ transition (Bousset and Diffley 1998; Donaldson et al. 1998a). Because late-firing origins are unable to initiate DNA replication in a $c d c 7-1$ mutant that is shifted to restrictive temperature in early- to mid-S phase, it appears that Cdc $7 \mathrm{p}$ activity is required throughout $\mathrm{S}$ phase and, in particular, to activate late-firing origins. Genetic evidence is consistent with the idea that the Dbf4/Cdc7 complex interacts with origin-bound components (Dowell et al. 1994; Fox et al. 1995; Loo et al. 1995; Hardy 1996), and both biochemical and genetic data suggest that MCM proteins are its physiological substrates (Hardy et al. 1997; Lei et al. 1997). Because the domain of Dbf4p that interacts with an ARS-bound complex is separable from the domain that binds Cdc7p, Dbf4p may target the kinase subunit to origins to ensure modification of origin associated substrates, although no direct demonstration of this association has been shown (Dowell et al. 1994; Hardy and Pautz 1996). Furthermore, it is not known at the moment the kinase complex binds origins, whether it remains origin bound until replication initiates, or whether the association itself is regulated, particularly at late-firing origins.

To examine the kinase activities required for the initiation of DNA replication in vitro replication assays have been particularly useful (for review, see Pasero and Gasser 1998). In a reconstituted vertebrate replication system, Laskey and colleagues have shown that Cyclin A/Cdk2 and Cyclin E/Cdk2 synergistically stimulate DNA replication in isolated $\mathrm{G}_{1}$-phase HeLa cell nuclei in the presence of a cytosolic extract (Krude et al. 1997).
Similarly, replication assays based on Xenopus egg extracts indicate an essential role for Cdk activity (Adachi and Laemmli 1994; Hua and Newport 1998; Walter et al. 1998). These results are consistent with yeast genetic studies that show that initiation requires a cyclin-dependent kinase (Schwob and Nasmyth 1993), yet none of these studies has assessed the role of the Dbf4/Cdc7 kinase in the promotion of DNA replication in vitro.

A recently developed replication system from yeast (Pasero et al. 1997) provides a unique opportunity to test the roles of CDC7 and CDC28 kinases in this event. Using extracts and nuclear templates from thermosensitive mutants, we confirm that a Clb/Cdk1 activity is not only essential, but is sufficient to promote the initiation of DNA replication in isolated $\mathrm{G}_{1}$-phase nuclei. Surprisingly, the presence of $\mathrm{Dbf} 4 / \mathrm{Cdc} 7$ kinase is dispensible in the nuclear extract, but is absolutely required in cis within the $G_{1}$-phase nuclei, to render the template initiation competent. We go on to show that a subpopulation of Dbf4p copurifies with an insoluble nuclear fraction and localizes to subnuclear foci that contain ORC in late $\mathrm{G}_{1}$. Unlike MCMs, Dbf4p requires ORC, but not Cdc6p, to associate with this Triton-insoluble chromatin fraction. Moreover, unlike Cdc45p (Zou and Stillman 1998), its association does not require activation of the $\mathrm{Clb} / \mathrm{Cdc} 28$ kinase. Finally, in vitro data indicate that the chromatin-bound fraction of Dbf4p can be displaced by DNA replication, resulting in its rapid degradation.

The data presented here support a model in which Dbf4p is synthesized in $G_{1}$ and targets the Cdc7 kinase to the pre-RC in a manner independent of $\mathrm{Clb} / \mathrm{Cdc} 28$ kinase. This appears to provide a high concentration of active Cdc7 kinase at its critical site of action, and to impede degradation of its labile regulatory subunit, Dbf4p. The regulated synthesis and origin association of this Cdc7p cofactor thus provides a second level of control over pre-RC assembly, independent of the $\mathrm{Clb} /$ Cdc28 kinase-regulated association of Cdc6p and MCMs.

\section{Results}

Cdc28p, but not Cdc7p, is required in trans to activate DNA replication in isolated yeast nuclei

We have shown previously that nuclei isolated from yeast cells arrested in late $G_{1}$ are able to initiate DNA replication in vitro in the presence of an S-phase nuclear extract, whereas $\mathrm{G}_{2}$ and $\mathrm{M}$-phase nuclei cannot (Pasero et al. 1997). Between $20 \%$ and $30 \%$ of the $G_{1}$-phase template (usually $100 \mathrm{ng}$ of genomic DNA) becomes fully substituted by BrdUTP, and is recovered after buoyant density gradient analysis as a heavy-light (HL) peak. To ensure that the template nuclei actually initiate replication during the in vitro replication assay, we use $\mathrm{G}_{1}$ phase nuclei from clb5clb6 deletion strains /designated $c l b 5,6 \Delta)$, which extends $G_{1}$ phase by $30 \mathrm{~min}$, such that pheromone-arrested cells do not progress to $S$ phase during the spheroplasting step. We use three criteria to monitor that the template nuclei have not entered $S$ 
phase; The absence of replication intermediates in either plasmid or genomic DNA as detected by 2D gel analysis (Pasero et al. 1997), the presence of Cdc6p, and the absence of $\mathrm{Clb} / \mathrm{Cdc} 28$ kinase activity as monitored by histone $\mathrm{H} 1$ phosphorylation (see Materials and Methods). Initiation in these nuclei is dependent on both the integrity of ORC and on the addition of an S-phase nuclear extract (Pasero et al. 1997), suggesting that a diffusible $\mathrm{S}$-phase factor activates one or more targets within the template nuclei.

Two Ser/Thr protein kinases, Cdc28p and Cdc7p, regulate the $G_{1} / S$ transition in yeast (Jallepalli and Kelly 1997), and could provide the diffusible SPF activity that stimulates initiation in $\mathrm{G}_{1}$-phase nuclei. To see whether histone $\mathrm{H} 1$ kinase levels correlate with the ability of an extract to stimulate replication, we tested nuclear extracts prepared from cells blocked at different points in the cell cycle with the replication assay. We find that an extract from early $\mathrm{G}_{1}$-phase cells, arrested because of an absence of the three $\mathrm{G}_{1}$ cyclins (GA-719), promotes a low level of semiconservative DNA replication in $c 1 b 5,6 \Delta \mathrm{G}_{1}$ nuclei (Fig. 1A). This correlates with the extract's low H1 kinase activity (Fig. 1A). Similar results are obtained with $\mathrm{G}_{1}$-phase extracts isolated from cells arrested with $\alpha$-factor or the cdc4-1 conditional arrest (Fig. 1D; Duncker et al. 1999). In contrast, extracts from cells synchronized in $S$-phase by $\alpha$-factor block-release (S) or arrested in $M$-phase with the $c d c 16-1$ mutation $(M)$, have high $\mathrm{H} 1$ kinase activity and efficiently trigger replication (Fig. 1A). Elsewhere we have shown that the histone $\mathrm{H} 1$ kinase assay in yeast nuclear extracts monitors almost exclusively the Cdc28 kinase (Duncker et al. 1999), as demonstrated previously for the Cdc2 kinase in $S$. pombe (Moreno et al. 1989).

Consistent with the idea that the B-type cyclin Clb5p is the critical regulator of $\mathrm{Cdc} 28 \mathrm{p}$ for the $\mathrm{G}_{1} / \mathrm{S}$ transition (Schwob et al. 1994), we found that an extract from a nonsynchronized culture that overexpresses CLB5 promotes initiation in $\mathrm{G}_{1}$-phase nuclei with nearly the same efficiency as an $S$ phase extract (data not shown). To demonstrate that the catalytic subunit, Cdc28p, is also required for activation of isolated $\mathrm{G}_{1}$-phase nuclei, and to address the role of Cdc7p in this process, nuclear extracts were prepared from wild-type (wt), and temperature-sensitive $c d c 28-4$ and $c d c 7-1$ cells synchronized in S -phase at permissive temperature. We monitor SPF activity in these extracts by integrating the peak of $\mathrm{HL}$ DNA recovered from $c 1 b 5,6 \Delta \mathrm{G}_{1}$-phase template nuclei incubated in these extracts at either permissive or restrictive temperatures. As shown in Figure 1B, inactivation of the kinase in the $c d c 28-4$ extract by incubation at $35^{\circ} \mathrm{C}$, resulted in a fivefold reduction in the $\mathrm{HL}$ peak, when compared with the same extract at $23^{\circ} \mathrm{C}$. In contrast, wild-type, $c d c 7-1$ and $d b f 4$ extracts were able to promote efficient semiconservative DNA replication at either temperature, as confirmed by the presence of a HL peak in the gradient analysis (Fig. 1B). Similarly, replication foci are detected in $c 1 b 5,6 \Delta \mathrm{G}_{1}$-phase nuclei incubated in either wild-type or cdc7 extracts, but not in a cdc28 extract, at $35^{\circ} \mathrm{C}$ (Fig. 1C). We conclude that an active Clb/Cdc28 kinase complex is necessary to promote replication in isolated $G_{1}$-phase nuclei.

To test whether an exogenous B-type cyclin/Cdk1 complex is sufficient to promote initiation, we have prepared a nuclear extract from cdc4-1 mutant cells, which arrest in late $G_{1}$ at restrictive temperature because of an accumulation of Siclp (Verma et al. 1997). Siclp is a specific inhibitor of the $\mathrm{Clb} / \mathrm{Cdc} 28$ kinase complex, and does not block activity of the $\mathrm{Cln} / \mathrm{Cdc} 28$ complex nor the mitosis-promoting Xenopus $\mathrm{CycB} / \mathrm{Cdc} 2$ complex (Duncker et al. 1999). As expected, the cdc4-1 extract supports only a low, background level of semiconservative DNA replication in $\mathrm{G}_{1}$-phase nuclei, slightly higher than that detected in total absence of extract (Fig. 1D,E, $O_{\text {; }}$ a similar experiment with $c 1 b 5,6 \Delta \mathrm{G}_{1}$ nuclei is quantified in Fig. 1A). Importantly, the addition of baculovirus-expressed Xenopus $\mathrm{CycB} / \mathrm{Cdc} 2$ kinase to the $c d c 4-1$ extract stimulates semiconservative replication in $\mathrm{G}_{1}$ phase nuclei to the same level achieved in a wild-type S-phase extract (Fig. 1, cf. D and E, O). The initiation steps could also be promoted in the $c d c 4-1$ extract by the addition of baculovirus-produced human CycE/Cdk2 or yeast Clb5/Cdc28 (data not shown). As expected, because of high levels of Siclp in the cdc4-1 extract, Clb5/ Cdc28 activates less efficiently than the heterologous kinases, which are insensitive to Siclp. Fully consistent with genetic studies showing that the mitotic B-type cyclins of yeast are able to complement the absence of both Clb5p and Clb6p (Schwob et al. 1994), we conclude that either an M- or S-phase cyclin/Cdk complex is sufficient to stimulate initiation in yeast nuclei in $G_{1}$-phase extracts. As shown in other systems, maximal replication still requires the presence of a cellular or nuclear extract, for the addition of cyclin B/Cdk kinase activity alone only modestly increases the HL peak above the background detected in buffer alone (Fig. 1E, shown for Xenopus $\mathrm{CycB} / \mathrm{Cdc} 2$ as $\boldsymbol{\Delta}$ vs. $\bigcirc)$.

\section{Replication is compromised in $G_{1}$-phase nuclei deficient for $\mathrm{Dbf} 4 \mathrm{p}$ or Cdc7p}

These results suggest that $\mathrm{Cdc} 7 \mathrm{p}$ is not required in trans to activate replication in $\mathrm{G}_{1}$-phase nuclei in vitro, leading us to suspect that Dbf4p and Cdc7p were being supplied by the template nuclei themselves. To test this hypothesis, we isolated $\mathrm{G}_{1}$-phase nuclei at permissive temperature from strains carrying thermosensitive alleles of these genes (cdc7-1 and $d b f 4)$, and tested their ability to replicate at permissive and restrictive temperatures. Whereas all nuclei replicate with comparable efficiency at $23^{\circ} \mathrm{C}$, the replication of mutant nuclei in the corresponding thermosensitive extract is significantly compromised at $35^{\circ} \mathrm{C}(\bullet$, Fig. $2 \mathrm{~B}, \mathrm{D})$. In contrast, wildtype $\mathrm{G}_{1}$-phase nuclei in the same $c d c 7-1$ extract produce equivalent $\mathrm{HL}$ peaks at both temperatures (Figs. 1 and 2A).

To examine whether the thermosensitivity of $c d c 7-1$ nuclei can be complemented in trans, we added a wildtype S-phase extract to the mutant template nuclei and again quantified replication by integration of the HL 
Figure 1. Cdc28p, but not $\mathrm{Cdc} 7 \mathrm{p}$, is required in trans to activate $\mathrm{G}_{1}$ nuclei. $(A)$ $\mathrm{G}_{1}$-phase nuclei prepared from clb5,6د cells (GA-769) arrested with $\alpha$-factor were used as template for in vitro replication in the presence of the indicated nuclear extracts. All reactions are performed in parallel with the same template nuclei. The extract labeled $G_{1}$ is prepared from preStart $c \ln 1 c \ln 2 c \ln 3$ GAL-CLN3 cells (GA719, see Materials and Methods); (S) A wild-type GA-59 strain synchronized in S phase by $\alpha$-factor block release; (M) cdc16-1 cells (GA-161) arrested in mitosis by a shift to $37^{\circ} \mathrm{C}$ after $\alpha$-factor synchronization. Replication was performed for $2 \mathrm{hr}$ at $30^{\circ} \mathrm{C}$ in the presence of BrdUTP and $\left[\alpha-{ }^{32} \mathrm{P}\right] \mathrm{dCTP}$ as described in Materials and Methods. The peak of semiconservative DNA replication (HL DNA) was integrated and converted to pmols on the basis of the specific activity of the incorporated dCTP (dark gray bars). The H1 kinase activity (light gray bars) was quantitated for a standard amount of extract, with the mitotic extracts as an arbitrary $100 \%$ (see Materials and Methods). Identical results were obtainedwith CLB5CLB6 nuclei synchronized by $\alpha$-factor block as template (see $D, E)$. $(B) \mathrm{G}_{1}$ nuclei from GA-769 cells

A
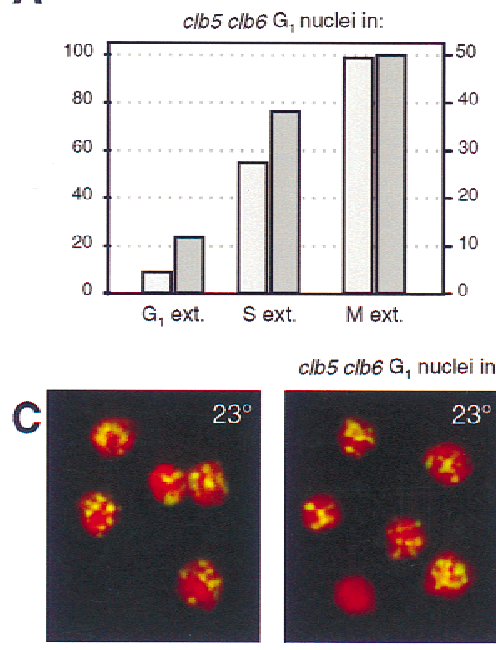

clb5 clb6 $\mathrm{G}_{1}$ nuclei in:
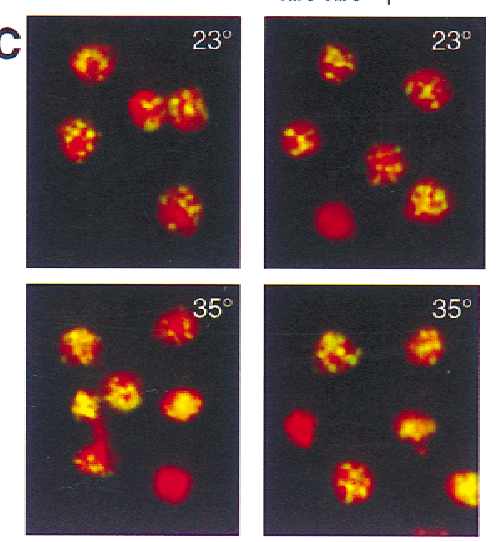

wt S extract

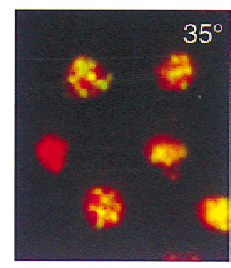

colc7 S extract
B
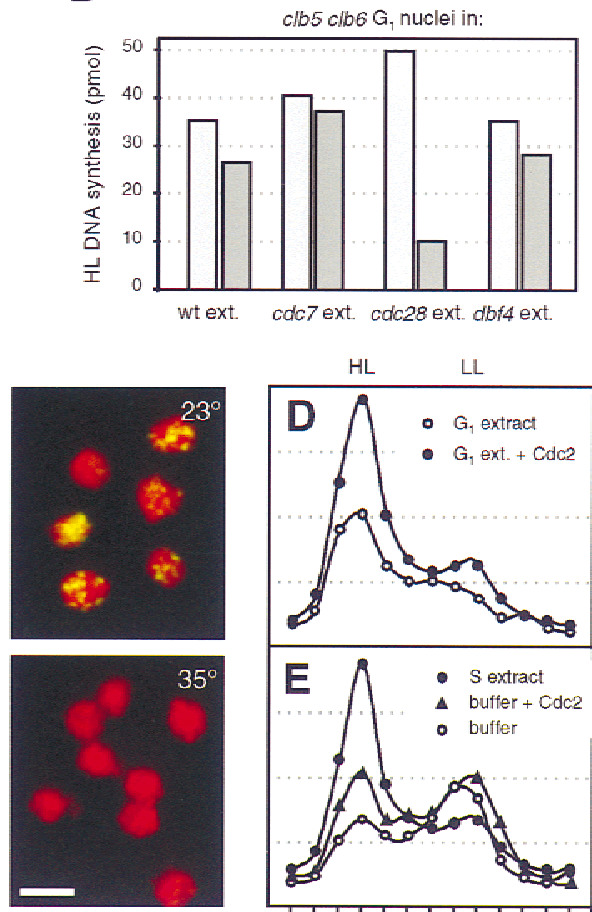

cdc28 S extract

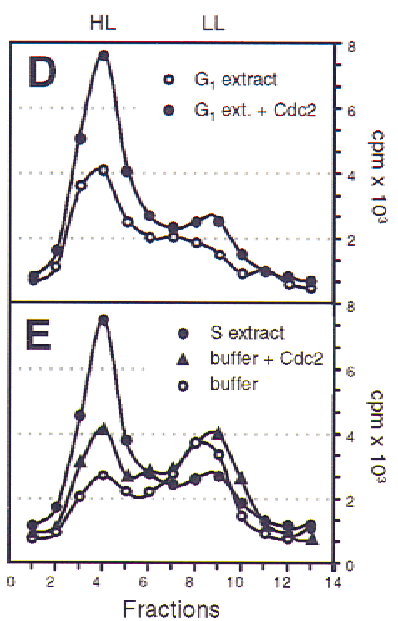

(clb5clb6) arrested with $\alpha$-factor were used in replication reactions at either $23^{\circ} \mathrm{C}$ (light gray bars) or $35^{\circ} \mathrm{C}$ (dark gray bars) with wild-type (GA-59), $c d c 7-1$ (GA-85), cdc28-4 (GA-112), or dbf4 (GA-849) S-phase extracts prepared as described in Materials and Methods. Incorporation into HL DNA was quantitated as in $A$. Extracts from $c d c 7-4$ mutants prepared at either $23^{\circ} \mathrm{C}$ or $37^{\circ} \mathrm{C}$ gave results identical to those shown here for $c d c 7-1$ (GA-85). (C) The same reactions performed in $B$ were carried out in the presence of DIG-dUTP instead of BrdUTP. The sites of incorporation were revealed by confocal microscopy of $\alpha$-DIG-FITC (yellow signal; Boehringer Mannheim) superimposed on genomic DNA (red). Bar, $2 \mu \mathrm{m}$. (D) Wild-type $\mathrm{G}_{1}$ nuclei prepared from $\alpha$-factor arrested GA-850 cells were allowed to incorporate BrdUTP as described in $A$, in a $\mathrm{G}_{1}$-phase extract prepared from GA-851 cells (cdc4-1) arrested for $4 \mathrm{hr}$ at $37^{\circ} \mathrm{C}$. A total of 10 units of baculovirus-expressed Xenopus $\mathrm{CycB} / \mathrm{Cdc} 2$ kinase was either added (O) or not (O) prior to the reaction. Shown is the profile of the $\left[\alpha{ }^{32} \mathrm{P}\right] \mathrm{dCTP}$ incorporated into genomic DNA after separation on a CsCl gradient; (HL) buoyant density of fully substituted DNA; (LL) buoyant density of unsubstituted DNA. (E) Replication assay with the same $\mathrm{G}_{1}$ nuclei as in $D$ incubated in a wild-type S-phase extract (GA-59; $)$, in buffer alone (O), or buffer supplemented with 10 units of CycB/Cdc2 kinase (A). Slightly less stimulation was observed on addition of an excess of recombinant human CycE/Cdk2 or Clb5/Cdc28 (data not shown).

peak recovered after gradient centrifugation. In contrast to $c d c 28-4$ nuclei (Fig. 2E), cdc7-deficient $\mathrm{G}_{1}$-phase nuclei could not be complemented by a wild-type S-phase extract (Fig. 2C,E). Western blots confirm the presence of Cdc7p and Dbf4p in nuclear extracts, although both proteins are relatively low in abundance (J.F-X. Diffley, pers. comm.; data not shown). Furthermore, the Cdc7p-deficient nuclei were even more severely compromised for replication in $c d c 28-4$ extracts at restrictive temperature (Fig. 2E). Taken together, this study of conditional mutant templates replicated in wild-type or mutant extracts leads us to conclude that $\mathrm{Dbf} 4 / \mathrm{Cdc} 7$ is required to promote DNA replication in vitro, yet it can only be effectively provided by the template nuclei. For $\mathrm{Clb} / \mathrm{Cdc} 28$ kinase, the opposite is true: The deficiency in template nuclei is readily complemented by an S-phase kinase in the extract, and $c d c 28$ deficiency in the extract cannot be compensated by use of Cdc $28^{+}$template nuclei (Figs. 1 and $2 \mathrm{E}$; data not shown).

\section{Dbf4p levels in $G_{1}$-phase nuclei correlate with competence for replication}

Northern analysis indicates that DBF4 is transcribed in a cell cycle-dependent manner, as are many genes implicated in DNA replication (Chapman and Johnston 1989). Because transcriptional variation does not necessarily result in fluctuating protein levels, we monitored Dbf4 protein by a Western blot of total protein extracts from a synchronized culture that bears an epitope-tagged copy of DBF4 under its own promoter (GA-850; Fig. 3A). $M A T$ a cells were arrested in mid- $\mathrm{G}_{1}$ phase with $\alpha$-factor, the pheromone was removed, and cells progressed synchronously through the cell cycle, as monitored by FACS analysis (Fig. 3B). The level of detectable Dbf4p drops significantly during $\alpha$-factor arrest and subsequently increases, peaking as cells pass the $\mathrm{G}_{1} / \mathrm{S}$ boundary (30-45 min). Dbf4p levels decrease again as $S$ phase is completed, and reach a minimum at the end of mitosis (75 


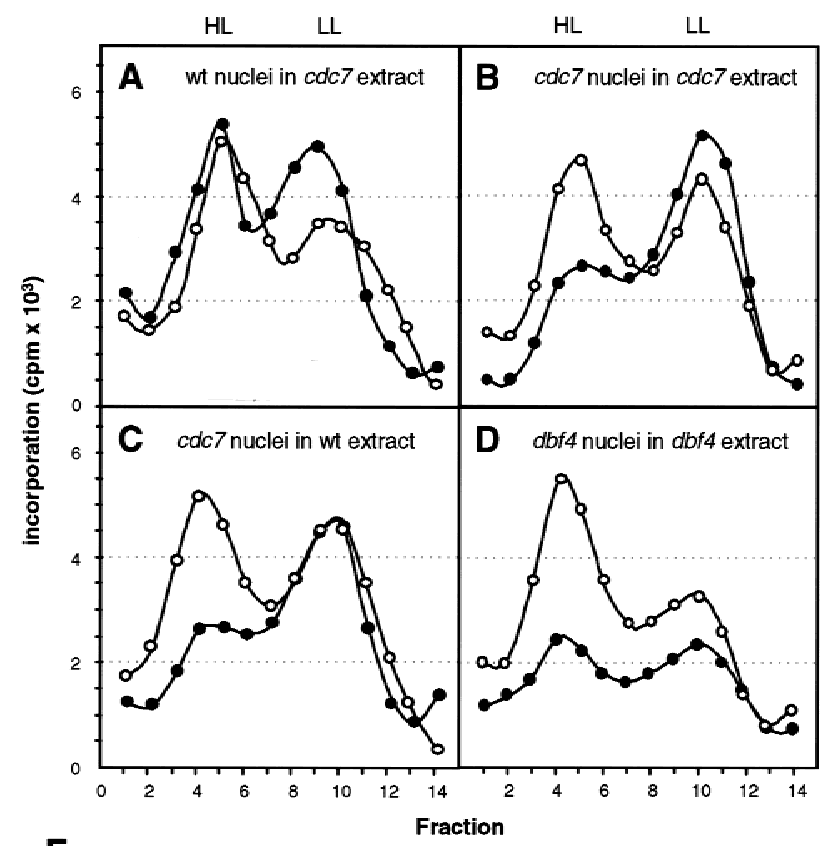

$E$

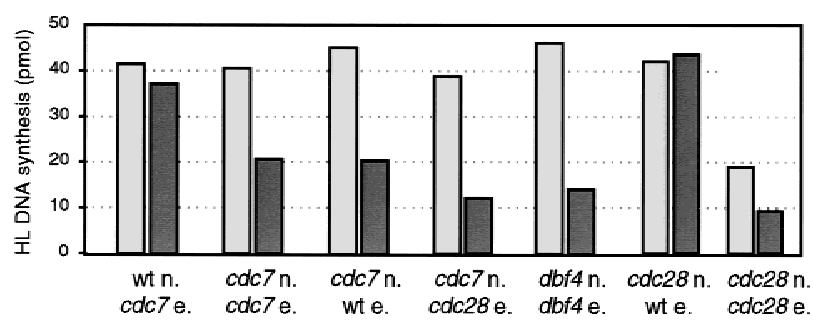

Figure 2. The Dbf4/Cdc7 complex is required in cis for the initiation of DNA replication. (A) In vitro DNA replication of wild-type $\mathrm{G}_{1}$-phase nuclei (GA-850) was performed as in Fig. 1A at either $23^{\circ} \mathrm{C}(\mathrm{O})$ or $35^{\circ} \mathrm{C}(-)$, in a cdc7-1 (GA-85) S-phase extract from cells arrested at $37^{\circ} \mathrm{C}$. Shown are profiles of the $\left[\alpha-{ }^{32} \mathrm{P}\right] \mathrm{dCTP}$ incorporated after buoyant density gradient separation. HL and LL are as in Fig. 1D. The increase in LL DNA may reflect elevated repair or nuclease activities at $35^{\circ} \mathrm{C}$. (B) Profile after buoyant density gradient separation of the $\left[\alpha-{ }^{32} \mathrm{P}\right] \mathrm{dCTP}$ incorporated into $c d c 7-1 \mathrm{G}_{1}$-phase nuclei (GA-366), prepared at permissive temperature after $\alpha$-factor arrest, and incubated in the same $c d c 7-1 \mathrm{~S}$-phase extract as in $A$. Replication was performed at either $23^{\circ} \mathrm{C}(O)$ or $35^{\circ} \mathrm{C}(\mathbf{O}) \cdot(C)$ Profile of $\left[\alpha^{-32} \mathrm{P}\right] \mathrm{dCTP}$ incorporation into the same $c d c 7-1 \mathrm{G}_{1}$-phase nuclei as in $B$ incubated in a wild-type (GA-59) S-phase extract. $(D)$ Profile after buoyant density gradient separation of the $\left[\alpha-{ }^{32} \mathrm{P}\right] \mathrm{dCTP}$ incorporated into $d b f 4$ (GA-849) $\mathrm{G}_{1}$-phase nuclei isolated from cells arrested with $\alpha$-factor at permissive temperature, and incubated in a $d b f 4$ (GA-849) S-phase extract prepared by $\alpha$-factor arrest release at permissive temperature (see Materials and Methods). Replication was carried out for $1 \mathrm{hr}$ at either $23^{\circ} \mathrm{C}(O)$ or $35^{\circ} \mathrm{C}(\mathbf{O})$. (E) The peak of HL DNA synthesis was integrated for the reactions shown in $A-D$ and converted to pmoles of DNA synthesized on the basis of the specific activity of $\left[\alpha-{ }^{32} \mathrm{P}\right] \mathrm{dCTP}$. Parallel reactions were performed with $\mathrm{G}_{1}$ phase nuclei from $c d c 7-1$ (GA-366) and cdc28-4 (GA-112) cells isolated after $\alpha$-factor arrest. These were incubated at $23^{\circ} \mathrm{C}$ (light gray bars) and $35^{\circ} \mathrm{C}$ (dark gray bars) in either a wildtype (GA-59) or a $c d c 28-4$ (GA-112) S-phase extract, and demonstrate that $c d c 28$-deficient nuclei can be complemented in trans. min after release, Fig. 3A). In contrast, Cdc7p levels do not fluctuate significantly at any point in the cell cycle. These results were also observed in cells synchronized by temperature-shift protocols (data not shown).

To test whether the $G_{1}$-phase synthesis of Dbf4p is required to render the template nuclei competent for initiation, we created a strain (GA-896) in which the genomic copy of DBF4 is under the control of the GAL1 UAS. This strain grows normally on galactose (see FACS profile in Fig. 3C), indicating that high DBF4 transcription rates are not detrimental to cell growth. When shifted to glucose-containing medium, Dbf4p expression is tightly repressed, and the cells accumulate at the $\mathrm{G}_{1} / \mathrm{S}$ transition with high $\mathrm{Clb} / \mathrm{Cdc} 28$ kinase activity, but lacking Dbf4p and Cdc7 kinase activity (see FACS analysis, Fig. 3C; R. Nougarède and E. Schwob, unpubl.). This block is partially reversible, for if galactose is added after a $3 \mathrm{hr}$ arrest on glucose, the cells that have not undergone a reductional anaphase replicate their DNA, resulting in a 2C DNA content (Fig. 3C). This suggests that Dbf4/Cdc7 kinase can execute its function even when synthesized after activation of the Clb5/Cdc28 kinase (further characterized in R. Nougarède and E. Schwob, unpubl.)

To isolate Dbf4p-depleted late $\mathrm{G}_{1}$-phase nuclei, we shifted GA-896 cells to glucose-containing medium for $2.5 \mathrm{hr}$, prior to nuclear isolation. As a control, $\mathrm{G}_{1}$-phase nuclei were isolated from an isogenic wild-type strain (GA-850) after the standard $\alpha$-factor arrest and spheroplast formation (see Materials and Methods). These wildtype $\mathrm{G}_{1}$-phase nuclei have low $\mathrm{H} 1$ kinase activity (Fig. $3 \mathrm{D})$, yet contain Dbf4p and replicate efficiently when incubated in an S-phase extract (see Fig. 3E, quantified in D). Dbf4p-depleted nuclei, on the other hand, support replication poorly: the peak of HL DNA is $~ 30 \%$ that recovered from control nuclei incubated in parallel. Importantly, unlike with wild-type $\mathrm{G}_{1}$-phase nuclei, this basal level cannot be stimulated by the addition of a wild-type S-phase extract (Fig. 3F, quantified in 3D), indicating that the competence of $\mathrm{G}_{1}$-phase nuclei for initiation correlates with the presence of Dbf4p. Consistent with this conclusion, we also observe low levels of replication in nuclei isolated from cells arrested by depletion of $\mathrm{G}_{1}$ cyclins (Pasero et al. 1997) and in nuclei isolated from cells exposed to $\alpha$-factor for $>90 \mathrm{~min}$, in which Dbf4p levels drop (data not shown). These results demonstrate a requirement for Dbf4p within the $G_{1}$-phase template nuclei, possibly as a component of the originbound pre-RC (Bousset and Diffley 1998; Donaldson et al. 1998a).

\section{Dbf4p localizes to subnuclear foci in an ORC2-dependent manner}

DNA replication occurs at discrete foci in yeast nuclei (Fig. 1C; Pasero et al. 1997), and immunostaining of Orc2p labels a similar subnuclear pattern that partially overlaps with newly synthesized DNA (Figs. 4C and 8A, below). This punctate pattern of Orc2p stands in contrast to the diffuse staining observed for more abundant replication proteins like Rpa2p or the $\mathrm{Cdc} 28$ kinase regula- 
Figure 3. Initiation of DNA replication in vitro depends on the presence of Dbf $4 \mathrm{p}$ in the template $\mathrm{G}_{1}$ nuclei. $(A)$ Dbf4p levels fluctuate during the cell cycle. A culture of GA-850 cells (carrying a Myc-tagged DBF4 gene) were arrested in $G_{1}$ phase for 90 min with $\alpha$-factor. Total protein extracts were prepared from the exponential culture (Exp), after $\alpha$-factor arrest $(\alpha \mathrm{F})$ and every $15 \mathrm{~min}$ after release from the block. After separation by SDS-PAGE, fractions were blotted with either 9E10 Mab (Myc epitope), a polyclonal antibody against Cdc7p (gift of C. Mann, Institute of Atomic Energy Research, Saclay, France) or TAT1 Mab (antitubulin) as a loading control. (B) FACS analysis of the DNA content of GA-850 cells during the $\alpha$-factor block-release experiment shown in $A$. (C) GA-896 cells that have a unique copy of DBF4 under the control of a galactose-inducible promoter, were grown exponentially on galactose-containing medium (YPGal) or arrested for 2, 3, 4, or $5 \mathrm{hr}$ on glucose-containing medium (YPD). DNA content analysis by FACS indicates arrest in $\mathrm{G}_{1}$ after $2 \mathrm{hr}$, and a peak at $0.5 \mathrm{C}$ corresponds to cells undergoing a reductional anaphase in the absence of Dbf $4 p$ after $3 \mathrm{hr}$ on YPD. One fraction of the culture was shifted back to YPGal after $3 \mathrm{hr}$ on YPD (YPD $3 \mathrm{hr}$, YPGal $2 \mathrm{hr}$ ) and FACS analysis shows that a significant proportion of the cells are able to enter $S$ phase. $(D)$ Nuclei were prepared from GA-850 cells arrested with $\alpha$-factor (wt) or from GA-896 cells arrested at the $\mathrm{G}_{1} / \mathrm{S}$ transition due to a lack of Dbf4p expression after $2.5 \mathrm{hr}$ on YPD (labeled Gal-DBF4). H1 kinase activity was monitored as described in Materials and Methods. We see low Clb/Cdc28 kinase activity in our $\mathrm{G}_{1}$-phase nuclei, and high kinase activity in the Dbf4p-depleted nuclei. Their ability to support semiconservative replication was monitored in standard reactions in a wild-type S-phase extract (GA-59; see F). (Dark gray bars) The integrated HL peak. (E,F) Profiles of the radioactivity recovered after buoyant density gradient analysis are shown for GA-850 $\mathrm{G}_{1}$ nuclei $(E)$ or for Dbf4p-depleted nuclei (GA-896, F), incubated under standard conditions either with a wild-type S-phase extract (GA-59, O) or without added extract (O). HL and LL DNA migrate in fractions $2-5$ and $8-10$, respectively.

tory subunit, Clb5p (Fig. 4B; data not shown). Consistent with its proposed role at origins, immunostaining for an epitope-tagged Dbf4p reveals subnuclear foci in smallbudded cells that resemble sites of DIG-dUTP incorporation during replication (Figs. 4A and 8B, below). Dbf4p, Clb5p, and Orc2p immunostaining patterns were scored for 300 cells that were coincidentally classed as being in $\mathrm{G}_{1}$ (no bud), early $\mathrm{S}$ (small bud), $\mathrm{G}_{2}$, or metaphase (large bud and dumbbell shaped). Discrete Dbf4p foci, like the diffuse staining of Clb5p, were detected in $80 \%$ of the small-budded cells, but in only $5 \%$ of dumbbell-shaped, metaphase cells (see arrowheads). In contrast, Orc2p foci persist through the cell cycle, being particularly visible in extended metaphase nuclei (Fig. 4C).

To see if Dbf4p and ORC foci coincide, we used a strain carrying differential epitope tags for Orclp and Dbf4p (GA-1123). There is substantial overlap between the two focal patterns in late $\mathrm{G}_{1}$ - and early S-phase nuclei (Fig. 4D-F), but only when the two primary antibodies are incubated sequentially with the fixed cells. When cells were labeled with both anti-epitope antibodies at once, individual cells were labeled either for Orc1p or for Dbf4p, but not for both (data not shown). Because mutually exclusive staining patterns are not observed for spatially discrete antigens (e.g., nuclear pores and Dbf4p), we consider this additional evidence that Orclp and Dbf4p are in close association.

To see whether the punctate Dbf4p staining requires the integrity of the ORC complex, Dbf4p was epitope tagged in both an orc2-1 mutant and an isogenic W303 background strain. Consistent with a partial penetrance of the orc2 phenotype at permissive temperature (Liang et al. 1995), we see that the Dbf4p staining pattern is significantly less punctate in the mutant even at $23^{\circ} \mathrm{C}$, 
Cdc7 kinase binds the prereplication complex in $G_{1}$
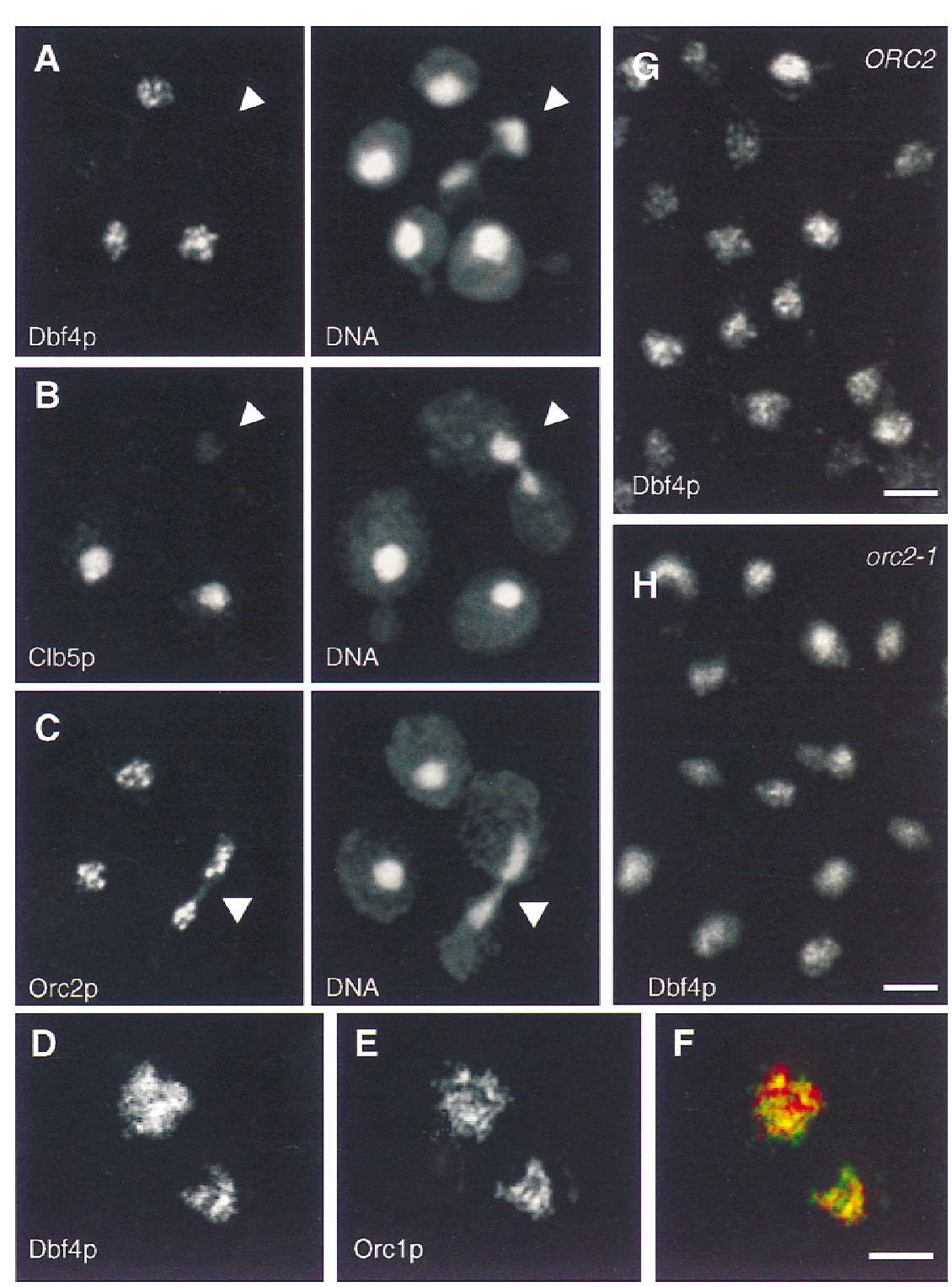

Figure 4. A fraction of Dbf4p localizes to subnuclear foci. $(A-C)$ Exponentially growing cells were fixed with $4 \%$ paraformaldehyde in YPD and were analyzed by immunofluorescence, as described in Materials and Methods. Dbf4p-Myc and Orc2-Myc were detected in the strains GA-850 and GA-893, respectively, with mAb 9E10. Clb5-HA was detected in GA-453 cells with mAb 12AC5. mAbs are detected by a DTAF-coupled goat anti-mouse secondary antibody. The background has been intentionally raised to show the contour of the cells so that the stage of the cell cycle can be deduced. In all cases, the $\mathrm{mAb}$ and secondary antibodies gave no significant signal for cells with no tagged construct. (Arrowheads) Mitotic cells. $(D, E)$ Dbf4p-Myc and Orclp-HA were detected in diploid GA-1123 cells by sequential incubation of the fixed spheroplasts with 9E10 (anti-Myc) and a Cy5-conjugated secondary antibody, followed by incubation with a rabbit serum specific for the HA epitope (Santa Cruz Biotechnologyl and a DTAF-conjugated secondary antibody. Staining patterns were mutually exclusive when both primary antibodies were used at once (see text). $(F)$ Merge of the signals in $D$ and $E$, Dbf4pMyc, and Orclp-HA are in red and green, respectively, with the region of overlap in yellow. $(G, H)$ Punctate pattern of Dbf4Myc is altered in orc2-1 cells. Exponential cultures of GA-850 cells (ORC2, G) and GA-1027 cells (orc2-1, H) were grown at $23^{\circ} \mathrm{C}$ and fixed. Dbf $4 \mathrm{p}-\mathrm{Myc}$ was detected by immunofluorescence as described in $A$. Typical fields of cells are shown. The cell cycle fluctuation in Dbf4p levels can be observed in these nonsynchronous populations. Noteworthy is the decrease in the punctate appearance of the Dbf4p signal in the orc2-1 strain that is otherwise isogenic to GA-850. Bars, $2 \mu \mathrm{m}$. when compared with the isogenic Orc2 ${ }^{+}$strain (Fig. 4G,H). Immunofluorescence of Orclp in this same background also shows a partially diffuse staining at $23^{\circ} \mathrm{C}$, and both Orclp and Dbf4p patterns are very diffuse in in the orc2-1 mutant at $37^{\circ} \mathrm{C}$, although signals for both antigens are weaker (data not shown). Because ORC and origins are still able to function at permissive temperature in an orc2-1 mutant, and because Dbf4p is at least partially associated with a chromatin fraction at $23^{\circ} \mathrm{C}$ (see Fig. 5), we interpret the diffuse pattern of immunostaining as a demonstration that a delocalized subpopulation of Dbf4p masks a residual focal pattern.

\section{Dbf4p cofractionates with Orc $2 p$ in an insoluble chromatin fraction}

In yeast, a simple chromatin-fractionation assay has been used to monitor the assembly of various compo- nents of the pre-RC (Donovan et al. 1997; Liang and Stillman 1997). After the lysis of spheroplasts and a lowspeed centrifugation step, a Triton-insoluble nuclear fraction retains between $5 \%$ and $10 \%$ of total cellular protein, but $>95 \%$ of the genomic DNA (labeled P, Fig. 5A). This so-called chromatin pellet can be fractionated further into soluble chromatin (Chr) and residual insoluble chromatin (here labeled Sc for scaffold) by digestion of the initial pellet with DNase I, followed by a low-speed centrifugation step.

When exponentially growing cells are fractionated by spheroplast lysis in Triton X-100, we recover all detectable Orc $2 p$ and Cdc6p in the membrane-free nuclear fraction (Fig. 5B, lane P). A small but reproducible fraction of total cellular Dbf4p is also recovered in the initial pellet, whereas the second subunit of the single-strand binding complex, Rpa2p, and tubulin are almost entirely solubilized. A triplet of nuclear pore proteins detected by 


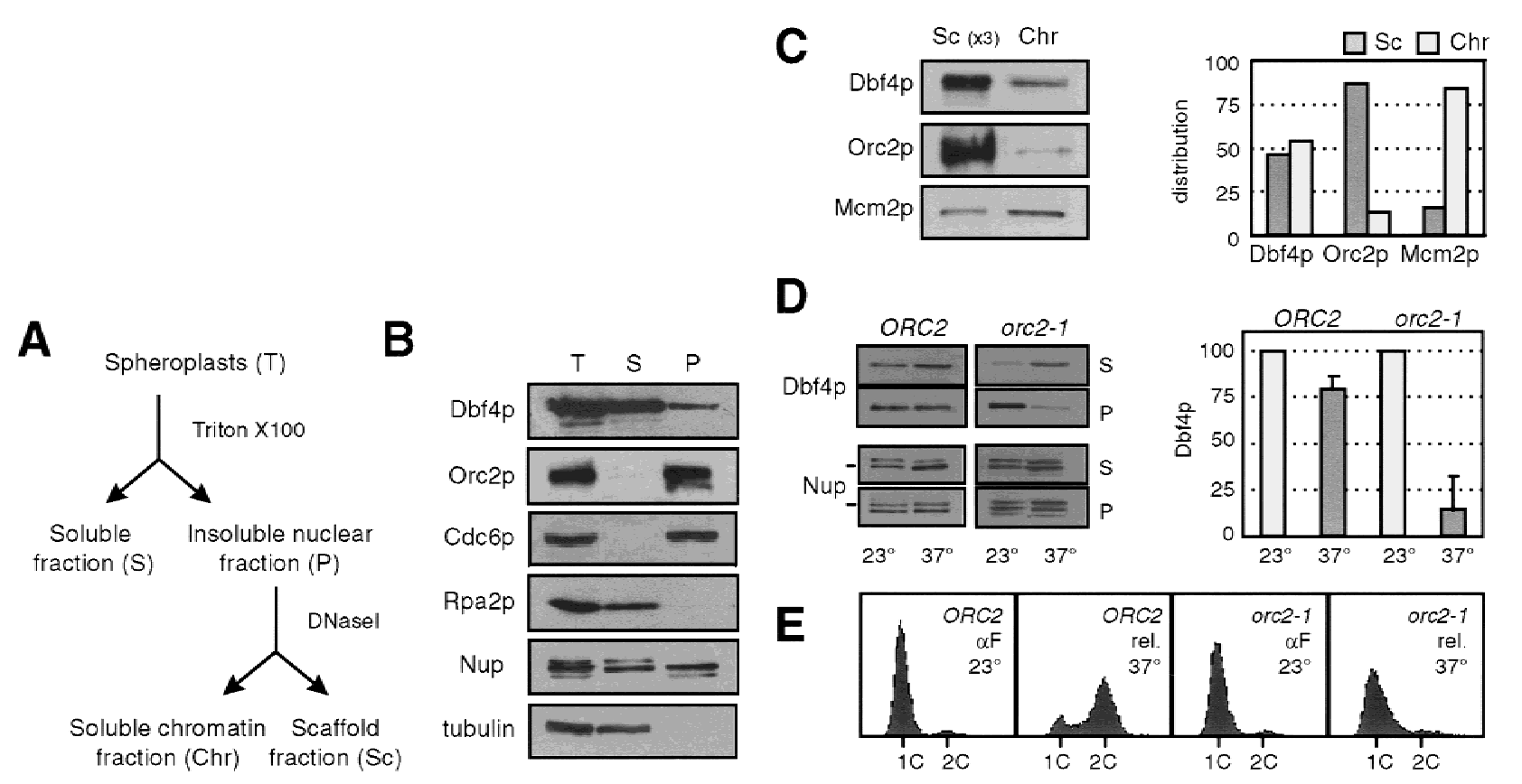

Figure 5. Dbf4p cofractionates with ORC in a scaffold fraction and associates with a chromatin pellet in an ORC-dependent manner. (A) The association of Dbf4p and other proteins with an insoluble nuclear fraction was analyzed basically as described in Donovan et al. (1997) and Liang and Stillman (1997). Spheroplasts prepared from nonsynchronized cells were lysed in a nonionic detergent. The insoluble nuclear fraction $(\mathrm{P})$ was separated from the soluble proteins $(\mathrm{S})$ by low-speed centrifugation and was resuspended in an equal volume as the supernatant. In some experiments, the pellet was further digested with DNase I and the solubilized chromatin fraction (Chr) was separated from the insoluble nuclear scaffold (Sc) by low speed centrifugation (see Materials and Methods). (B) Chromatin assays were performed on exponentially growing cultures of GA-850 (Dbf4-Myc) and GA-893 (Orc2-Myc). The antibodies used for Western blot analysis of total protein extracts $(\mathrm{T})$, supernatant $(\mathrm{S})$, and insoluble nuclear $(\mathrm{P})$ fractions are described in Fig. 3 and in Materials and Methods. Mab414 (Berkeley Antibody Inc., CA) detects the nuclear pore proteins Nup100, Nup116 and Nup145, of which the central band (Nup116, indicated with bar) reproducibly partitions equally between soluble and insoluble nuclear fractions, providing an internal control for loading. In this panel the strain GA-893 (Orc2-Myc) was used for the detection of Orc2p. (C) Insoluble nuclear fraction from an exponentially growing culture of GA-850 cells (Dbf4-Myc) was further fractionated by DNase I digestion. Very little protein is recovered in the final scaffold pellet and therefore three times the amount was loaded to facilitate quantitation. Orc2p is detected with anti-Orc2p (JAb12, gift of J. Diffley), Mcm2p is detected with a goat polyclonal serum, YN-19, (Santa Cruz Antibodies, CA) and Dbf4-Myc with 9E10 on identical scaffold (Sc) and soluble chromatin (Chr) samples. Quantitation of protein distribution between the two fractions is shown on the graph at right. (D) Isogenic wild-type (GA-850) and orc2-1 (GA-1027) cells were arrested in $G_{1}$ phase at $23^{\circ} \mathrm{C}$ with $\alpha$-factor, were incubated at $37^{\circ} \mathrm{C}$ for $30 \mathrm{~min}$ in the presence of $\alpha$-factor and were released from the block at $37^{\circ} \mathrm{C}$ for $60 \mathrm{~min}$. After spheroplasting, permeabilization of the cells with Triton X-100 and centrifugation, the amount of Dbf4p in S and P fractions was quantitated by immunoblotting in three independent experiments. One-tenth of the supernatant was loaded on the gel relative to the pellet fraction. Nucleoporins (Nup) were used as loading control and for normalization. (E) FACS analysis of a typical experiment in which orc2-1 and wild-type cells were arrested with $\alpha$-factor at permissive temperature $(\alpha \mathrm{F})$ and released for $60 \mathrm{~min}$ at $37^{\circ} \mathrm{C}$ (rel.).

a commercial anti-pore monoclonal antibody (mAb 414, Berkeley Antibody, Inc., see Rout and Blobel 1993) serve as loading controls, particularly as the middle band, Nup116, is almost equally represented in both soluble and bound fractions (Fig. 5D, see bars). Following the DNase I fractionation step, which releases DNA, histones, and most of the Mcm 2 protein from the initial pellet, nearly all of Orc2p and $\sim 50 \%$ of the Dbf $4 p$ are recovered in the insoluble scaffold fraction (see Fig. 5C). This partitioning is consistent with the proposal that even in a random population, a large fraction of the chromatin-associated Dbf4p is tightly bound to the ORC complex, because scaffold fraction contains $<2 \%$ of the total cellular protein, but the vast majority of ORC. It is not known whether the Dbf4p that is released at this final step is associated with the Dbf4/CDC7 substrate
Mcm2p, which, unlike ORC, is enriched in soluble chromatin (Fig. 5C, Chr).

\section{Dbf $4 p$ requires ORC, but not Cdc6p, to bind chromatin}

To examine whether the association of Dbf $4 \mathrm{p}$ with the insoluble nuclear pellet requires an intact ORC complex, we performed the chromatin fractionation assay on synchronized cultures of the orc2-1 mutant and an isogenic $\mathrm{Orc2}^{+}$strain (ORC2). In Xenopus extracts, as in yeast, it has been shown that the depletion or inactivation of ORC or Cdc6p precludes formation of a functional preRC (Diffley et al. 1994; Carpenter et al. 1996; Cocker et al. 1996; Coleman et al. 1996). Because a temperature shift in the orc2-1 mutant appears to disrupt the ORC 
complex entirely (Santocanale and Diffley 1996), we first synchronized orc2-1 and wild-type cultures in $\mathrm{G}_{1}$ by pheromone arrest at $23^{\circ} \mathrm{C}$, and then shifted a fraction of each culture to $37^{\circ} \mathrm{C}$ and released the cells from pheromone arrest. One hour after release, the mutant arrests at the $G_{1} / S$ boundary due to inactivation of Orc $2 p$, whereas the ORC2 strain recovers from $\alpha$-factor and progresses into $S$ phase (see FACS analysis of arrested and released cultures, Fig. 5E). Cells arrested in early $G_{1}$ at permissive temperature and in late $G_{1}$ at nonpermissive temperature were fractionated into the soluble and insoluble nuclear fractions and probed for Dbf4p and nuclear pore. At $23^{\circ} \mathrm{C}$, Dbf $4 \mathrm{p}$ is efficiently retained in the insoluble pellet of both the mutant and wild-type strains, whereas after inactivation of Orc $2 p$ by a shift to $37^{\circ} \mathrm{C}$, Dbf4p is almost entirely displaced to the soluble fraction (Fig. 5D; cf. P and S). The displacement is not due to the elevated temperature per se, because Dbf4p remains chromatin bound in the ORC2 background at $37^{\circ} \mathrm{C}$, and is efficiently recovered in the chromatin fraction of cdc6-1 cells arrested at $37^{\circ} \mathrm{C}$ (Figs. 5D and 6B). Cdc6p, as expected, is released from the pellet in both mutant strains (data not shown). Quantitation of the amount of Dbf $4 \mathrm{p}$ recovered in the insoluble nuclear pellet from three independent experiments is shown in Figure 5D, normalized to the recovery of the Nup116 band. Because the ORC2 strain progresses into $\mathrm{S}$ phase after removal of $\alpha$-factor, is is not strictly comparable with the $\mathrm{G}_{1} / \mathrm{S}$ arrest of the orc2-1 strain, yet results presented below show that Dbf4p remains associated with the insoluble nuclear pellet throughout late $G_{1}$ and $S$ phase in $\mathrm{Orc}^{+}$backgrounds (see Figs. 6 and 7). Thus, our results show that the association of newly synthesized Dbf4p with the insoluble pellet after recovery from pheromone arrest, is sensitive to the integrity of ORC. Because the level of Dbf4p is low in the $\alpha$-factor-arrested cells used in panel D, we also tested exponentially growing wild-type and orc2-1 strains as controls for this experiment. Again, the distribution of Dbf4p between soluble and insoluble fractions was quantified and normalized to the nuclear pore signal. No temperature-induced release of Dbf4p is observed in wild-type cells, although the amount retained in the insoluble nuclear pellet drops by $80 \%$ when the orc2-1 strain is shifted to $37^{\circ} \mathrm{C}$ (data not shown).

\section{Cdc6p and MCM loading are not essential for Dbf4p association with nuclear chromatin}

Whereas the ORC dependence shown in Figure 5 is consistent with the hypothesis that Dbf4p binds directly to the origin complex, Dbf4p might also associate through the MCM complex, because MCMs associate with the pre-RC prior to $\alpha$-factor arrest and remain chromatin bound despite Cdc6p release (Donovan et al. 1997; Hua and Newport 1998). For this reason, we tested whether Cdc6p, and thereby MCM loading, is necessary for the association of Dbf4p with the insoluble nuclear fraction.

The most efficient manner to prevent MCM loading is
A

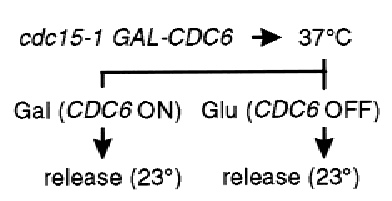

B
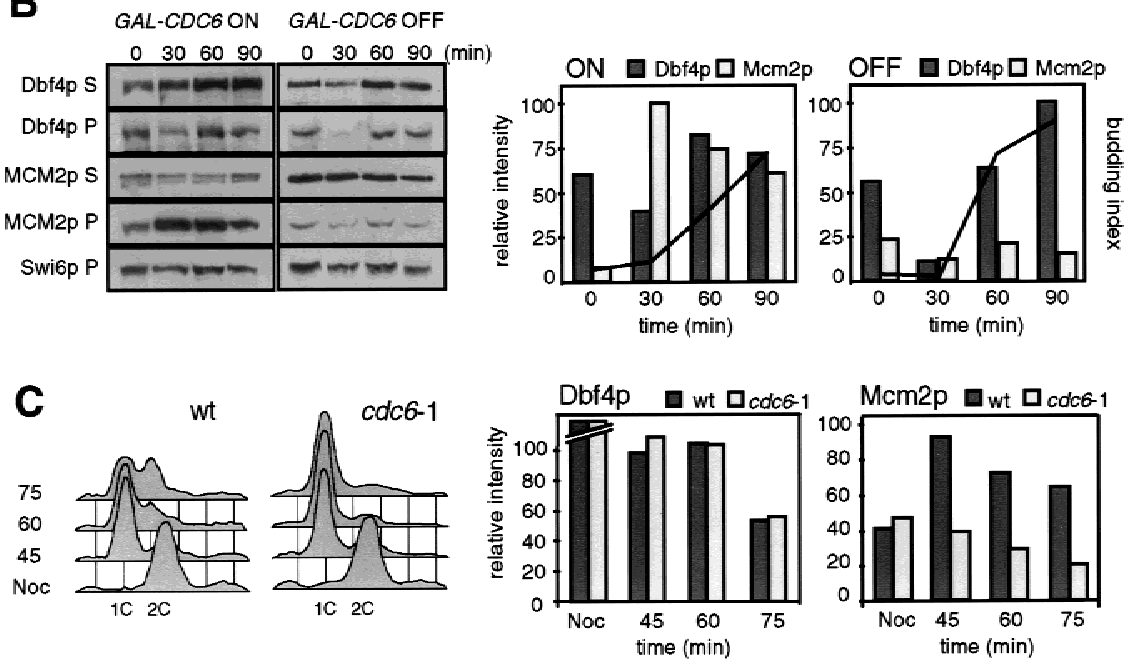

Figure 6. Dbf $4 p$ does not require Cdc6p or MCM loading to associate with the insoluble nuclear fraction. (A) GA-1213 cells (cdc15, GAL-CDC6) grown on galactose were arrested in late $M$ phase for $2 \mathrm{hr}$ at $37^{\circ} \mathrm{C}$. Half of the culture was maintained for another hour in the same medium at $37^{\circ} \mathrm{C}$ whereas $2 \%$ glucose was added to the other half to shut off the GAL-CDC6 promoter. Cells were then released from the $c d c 15$ arrest in the presence (GAL-CDC6 $\mathrm{ON}$ ) or the absence (GAL-CDC6 OFF) of Cdc6 function. Samples were taken at regular time intervals and the DNA content of the cells was analyzed by FACS. $(B)$ Chromatin assays were performed on the samples described above and the distribution of Dbf4p and $\mathrm{Mcm} 2 \mathrm{p}$ in the soluble and insoluble nuclear fractions was analyzed by Western blot. The amount of Dbf4p and $M c m 2 p$ in the insoluble nuclear fraction was determined relative to Swi6, which was used as a loading control. The percentage of budded cells is shown for the same time points. (C) GA1026 cells grown at $25^{\circ} \mathrm{C}$ were arrested for $1 \mathrm{hr}$ with $20 \mu \mathrm{g} / \mathrm{ml}$ nocodazole and were shifted to $37^{\circ} \mathrm{C}$ for another hour in the presence of nocodazole before being released from the arrest at $37^{\circ} \mathrm{C}$. Samples were taken just prior to (Noc) and at regular time intervals after the release. Position of cells in the cell cycle was determined by FACS and the distribution of Dbf4p and Mcm2p in the insoluble nuclear fraction, relative to p55 ${ }^{\mathrm{RN} a s e}$, was analyzed by Western blot as described in Materials and Methods. The quantitation represents the mean value for two experiments. Relative Dbf4p levels for wild-type and cdc6-1 Noc samples are 160 and 220, respectively. 
Figure 7. The association of Dbf4p with chromatin is cell cycle regulated. (A) GA850 cells arrested in $G_{1}$ with $\alpha$-factor were released into $S$ phase, and aliquots were taken at regular time intervals. Cells were spheroplasted and fractionated into a soluble $(\mathrm{S})$ and insoluble nuclear $(\mathrm{P})$ fraction as described in Materials and Methods. The insoluble nuclear fraction was resuspended in $1 / 10$ the volume of the supernatant. Equal amounts of proteins were loaded for each time point, and distribution of Dbf4p, $\mathrm{Mcm} 2 \mathrm{p}$, Orc2p, and tubulin was probed by Western blot. (B) FACS analysis of DNA content was performed on the cells described in $A$, as they synchronously traversed the cell cycle. $(C)$ Quantitation of the relative amount of $\mathrm{Dbf} 4 \mathrm{p}(\mathrm{O})$ and $\mathrm{Mcm} 2 \mathrm{p}$ (-) in the insoluble nuclear fractions through the cell cycle, derived from the data shown in $A$. (D) GA-980 cells, that produce a nondegradable form of Siclp in the presence of galactose, were grown on YPD and were arrested in $\mathrm{G}_{1}$ with $\alpha$-factor for $90 \mathrm{~min}$. Cells were then shifted to galactose-containing medium (YP-Gal) for $30 \mathrm{~min}$ in the presence of $\alpha$-factor before being released from the pheromone arrest in YP-Gal for 2 hr. These cells block irreversibly at the $G_{1} / S$ transition with high Siclp levels. In parallel, $\alpha$-factor arrested GA-980 cells were grown on YPD and released into $S$ phase until the appearance of small buds, indicative of entry into $S$ phase. $(E)$ FACS analysis of GA980-arrested cells from $D$. (F) GA-980 cells arrested as described in $D$ were spheroplasted and fractionated as described above (Fig. 5A) by the chromatin assay. The soluble ( $S$, light gray bars) and insoluble nuclear ( $\mathrm{P}$, dark gray bars) fractions were analyzed by Western blot for Dbf4-Myc, and for p55 ${ }^{\mathrm{RNase}}$ (Karwan et al. 1990). The distribution of Dbf4p was quantitated by immunoblotting and normalized to p55 ${ }^{\text {RNase }}$, which shows no cell cycle variation. $(G)$ GA-850 cells were arrested in $G_{1}$ for $2 \mathrm{hr}$ with $\alpha$-factor (lane 1) and were released into $S$ phase for 30 min in the presence (lane 3) or the absence (lane 2) of $200 \mu \mathrm{m}$ of $\mathrm{HU}$ and the association of Dbf $4 \mathrm{p}$ and Mcm2p with the insoluble nuclear fraction (P) was analyzed as described above. The same experiment was performed by arresting exponentially growing GA-850 cells (lane 4) and an isogenic strain deficient for the rad53 checkpoint function (GA-1212, lane 5) for $2.5 \mathrm{hr}$ with $200 \mu \mathrm{m}$ HU. (H) FACS analysis of samples described in $G$.

to deplete Cdc6p from cells as they pass from mitosis into $G_{1}$. This can be achieved by placing the genomic CDC6 gene under control of the GAL1 UAS, which allows complete transcriptional repression by growth on glucose. This is done in a $c d c 15-1$ strain, which permits synchronization in mid-metaphase by shifting to $37^{\circ} \mathrm{C}$. A random culture on galactose was thus arrested prior to anaphase by a $2 \mathrm{hr}$ temperature shift, whereas half of the culture was switched to glucose medium for an additional hour. Release by a return to $23^{\circ} \mathrm{C}$ allowed the cells to progress synchronously into $\mathrm{G}_{1}$, either in the presence (galactose medium) or absence (glucose medium) of Cdc6p. FACS analysis confirmed both the efficiency of the arrest and the timing of $\mathrm{G}_{1}$.

Cells were fractionated by spheroplasting and Tritonlysis as described above (see Fig. 5A), and the association of Dbf4p and Mcm2p with the insoluble nuclear fraction
(P) was monitored by Western blot. In this case, Swi6p serves as the loading control, for it remains chromatin associated independent of the pre-RC. When Cdc $6 \mathrm{p}$ is present $(\mathrm{ON}) \mathrm{Mcm} 2 \mathrm{p}$ associates rapidly with the chromatin fraction peaking between 30 and 45 min after release, whereas Dbf4p loads more slowly, peaking at 60min postrelease (Fig. 6B). When no Cdc6p is present (see $\mathrm{OFF}), \mathrm{Mcm} 2 \mathrm{p}$ does not bind the insoluble nuclear fraction, whereas Dbf4p association is, proportionately, even more efficient in the absence of Cdc6p (Fig. 6B). A drop in the level of bound Dbf4p at 30-min postrelease is seen in both the $\mathrm{Cdc}^{+}$and Cdc6-depleted cells, and may reflect a point in late telophase/early $G_{1}$, at which time Dbf4p is specifically depleted from the chromatin fraction. These results clearly indicate that MCM complex loading is not a prerequisite for the association of Dbf4p with the chromatin pellet. 
Further evidence that Dbf4p loading does not require pre-RC formation was obtained by use of a cdc6-1 temperature-sensitive strain. Again, cells were synchronized in mitosis at permissive temperature, and then released from the nocodazole block at restrictive temperature. The cdc6-1 cells accumulate at the $\mathrm{G}_{1} / \mathrm{S}$ boundary, whereas the isogenic CDC6 strain progresses through $\mathrm{G}_{1}$ and into $S$ phase (see FACS analysis in Fig. 6C). The distribution of Dbf4p and $M c m 2 p$ between the soluble fraction and the insoluble nuclear pellet was determined by Western blot as described above, with an abundant cellular RNase (p55, Karwan et al. 1990) to normalize recovery. Again, we observe that $\mathrm{Mcm} 2 \mathrm{p}$ loading is entirely dependent on a functional Cdc6p, whereas Dbf4p associates with the chromatin pellet in a Cdc6p-independent fashion (Fig. 6C).

\section{Association of Dbf4p with chromatin fluctuates through the cell cycle, but is independent of Clb/Cdc28 kinase}

Although ORC association with the insoluble nuclear fraction is constant through the cell cycle (Fig. 7A), the association of Cdc6p, MCMs, and Cdc45p with the pre$\mathrm{RC}$ is carefully controlled. Moreover, in the case of these latter three components, $\mathrm{Clb} / \mathrm{Cdc} 28$ kinase activity plays an important regulatory role, either preventing (for Cdc6p and MCMs) or promoting (for Cdc45p) their assembly at origins. To examine the cell cycle and Cdc28 kinase dependence of the association of Dbf4p with this insoluble nuclear fraction, we have fractionated wildtype cells carrying a Myc-tagged Dbf4p as they progress synchronously through the cell cycle following an $\alpha$-factor arrest (see Fig. 7B for FACS analysis of the culture). Identical samples were probed with antibodies recognizing the Myc-tagged Dbf4p, Mcm2p, Orc2p, and tubulin (Fig. 7A). As noted above, the total amount of Dbf4p present in the cell drops significantly on $\alpha$-factor arrest, and fluctuates during the cell cycle, peaking in early $S$ phase. Consistently, Dbf4p is most highly represented in the chromatin-bound fraction at the $G_{1} / S$ transition (see 30-min time point), and appears to be displaced gradually throughout $S$ phase, reaching a minimum at mitosis $(70-$ 80 min postrelease, Fig. 7A). Mcm2p, on the other hand, loads prior to $\alpha$-factor arrest, remains associated during the arrest/release protocol, and then becomes rapidly displaced as DNA replication proceeds (40-50 min postrelease). Quantitation of the bound fractions of Dbf4p and Mcm2p through this synchronous cell cycle reveals asynchrony in the association and loss of Dbf $4 p$ and $\mathrm{Mcm} 2 \mathrm{p}$ from the pellet fraction: $\mathrm{Mcm} 2 \mathrm{p}$ association and release precedes that of Dbf4p by 15-30 min (Fig. 7C). Although the fluctuation of Dbf4p in the insoluble nuclear chromatin closely follows variations in total Dbf4p levels, we note that during $S$ phase the bound fraction of Dbf4p is significantly more stable that the unbound fraction (40-60 min postrelease, Fig. 7A). Thus, together with the fact that soluble Dbf4p is more readily degraded in vitro (Fig. 8), it appears that the association of Dbf4p with nuclear chromatin contributes toward its stabilization.

It is well established that the assembly of the pre-RC is prevented by high $\mathrm{Clb} / \mathrm{Cdc} 28$ kinase activity (Tanaka et al. 1997), whereas the loading of Cdc45p at origins was recently shown to require $\mathrm{Clb} / \mathrm{Cdc} 28$ kinase activation (Zou and Stillman 1998). Because the association of Dbf4p with the insoluble nuclear fraction peaks near to the $\mathrm{G}_{1} / \mathrm{S}$ transition, it was important to test whether this binding also requires an active $S$-phase Cdk kinase. To this end, we analyzed the distribution of Dbf4p between the insoluble and soluble fractions, in cells that express a nondegradable form of the $\mathrm{Clb} / \mathrm{Cdc} 28$ inhibitor Siclp under the control of the GAL1 UAS (GA-980). Exponentially growing GA-980 cells were synchronized with $\alpha$-factor and released into galactose medium, which induces SIC1 and thus arrests cells at the $\mathrm{G}_{1} / \mathrm{S}$ transition with no Clb/Cdc28 activity (see scheme and FACS profiles, Fig. 7D,E). As shown above, the Dbf4p level is very low in $\alpha$-factor-blocked cells, yet a significant fraction of the remaining protein cofractionates with ORC (see P, Fig. 7F,G). As cells traverse late $\mathrm{G}_{1}$ and arrest with high Siclp levels (Sic1), Dbf4p levels increase, and $\sim 10 \%$ of the cellular Dbf4p is tightly associated with the insoluble nuclear fraction. This is true despite a complete absence of Clb/Cdc28 activity (Fig. 7F; see also Duncker et al. 1999). Thus, association of Dbf4p occurs independently of Clb/Cdk activation.

To examine the behavior of Dbf4p following the activation of $\mathrm{Clb} / \mathrm{Cdc} 28$ kinase, a part of the $\alpha$-factor-arrested culture was released and allowed to progress into $S$ phase. A third aliquot was arrested in $S$ phase by the addition of the ribonucleotide reductase inhibitor, hydroxyurea (HU). All cultures were subjected to the identical fractionation protocol, and probed for Dbf4p, Mcm2p, and the RNase p55. We observe an increase in the association of Dbf4p with the insoluble nuclear fraction in $\mathrm{S}$ phase, although this is compromised when cells are arrested with HU (Fig. 7G,H). The association of $\mathrm{Mcm} 2 \mathrm{p}$ with the insoluble fraction, on the other hand, does not vary significantly under these conditions. Although both the synchronous S-phase population and the HU-arrested population have high $\mathrm{Clb} / \mathrm{Cdc} 28$ kinase activity, the HU arrest additionally provokes a cell cycle checkpoint response that activates Mecl and Rad53 kinases (cell cycle stages are confirmed by FACS analysis; Fig. $7 \mathrm{H})$. Because it has been shown that HU induces a Rad53p-mediated phosphorylation of Dbf4p (Bousset and Diffley 1998; Santocanale and Diffley 1998), we examined whether this modification might be responsible for the release of Dbf4p from the insoluble nuclear pellet when cells are exposed to HU. An HU arrest experiment was therefore performed with the mec2-1 allele of $R A D 53$, which fails to activate Rad53 kinase activity in response to HU (Weinert et al. 1994). Fractionation into the insoluble nuclear pellet and supernatant shows that under these conditions Dbf4p remains chromatin associated (Fig. 7G, lane 5), consistent with the proposal that Rad53, but not Cdc28 kinase, controls the association of Dbf4p with the replication origin complex. In conclu- 
Figure 8. The chromatin-associated fraction of Dbf4p is displaced on initiation. $(A)$ An in vitro DNA replication assay with $G_{1}$ nuclei prepared from $\alpha$-factor arrested GA893 cells was performed to localize Orc2Myc relative to the sites of incorporation of DIG-dUTP. The in vitro replication reaction with DIG-dUTP and its detection were performed as described in Figs. 1C and 4C. Bar, $2 \mu \mathrm{m}$. (B) A similar experiment with $\mathrm{G}_{1}$ nuclei (GA-850) shows that the Dbf4-Myc staining in replicating nuclei is inversely proportional to the amount of DIG-dUTP incorporated. The replication assay was stopped by addition of para-formaldehyde and both the sites of DIG-dUTP (green) incorporation and of Dbf4-Myc (red) localization were detected by IF. Different replicating nuclei presenting increasing levels of DIG-dUTP incorporation are shown. Bar, 2 $\mu \mathrm{m} .(C)$ An in vitro DNA replication assay was performed for $2 \mathrm{hr}$ with GA-850 $\mathrm{G}_{1}$ nuclei, in the presence (+aph) or the absence (-aph) of aphidicolin. The nuclei were permeabilized with $1 \%$ Triton X-100 before (lanes labeled $\mathrm{G}_{1}$ ) or after the reaction and the presence of Dbf4p and Rpa2p was detected in the insoluble nuclear $(\mathrm{P})$ and the soluble (S) fractions by immunoblotting. If replication proceeds (-aph), then most of Dbf $4 p$ is degraded by the end of the 2-hr incubation. If it is blocked $(+a p h)$, then the chromatin-associated Dbf $4 \mathrm{p}$ remains. Because the ratio of insoluble nuclear to soluble Dbf4p is higher in isolated nuclei than in whole cell extracts, some soluble Dbf4p may be lost during nuclear isolation.
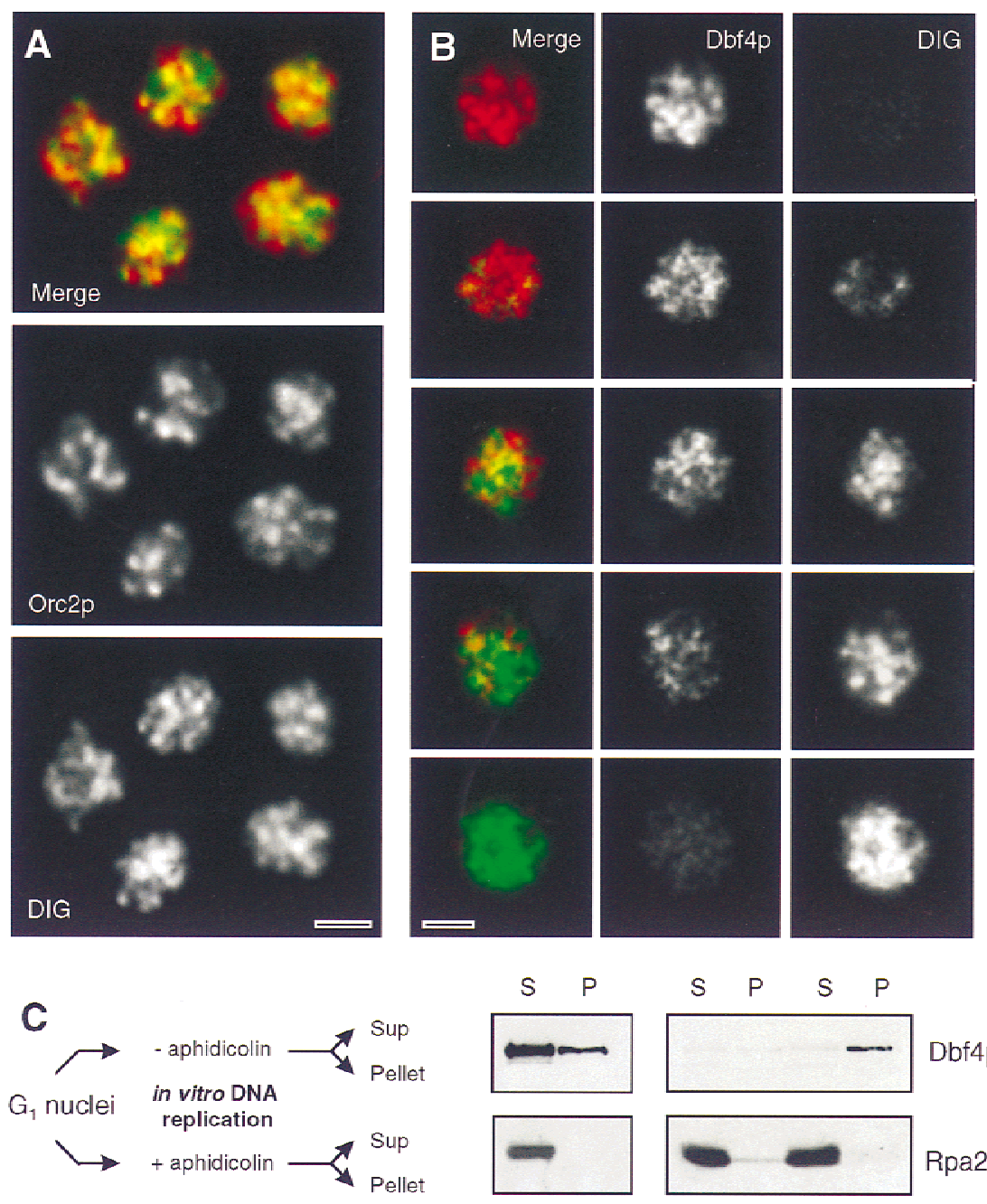

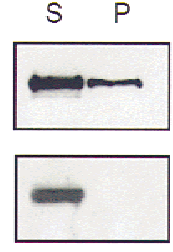

$\mathrm{G}_{1} \mathrm{n}$.

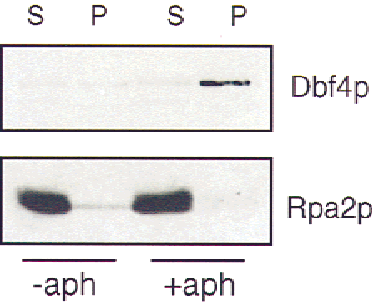

sion, although the amount of Dbf4p that is associated with the insoluble nuclear fraction varies through the cell cycle, it appears to neither require nor be impeded by $\mathrm{Clb} / \mathrm{Cdc} 28$ kinase activity.

\section{Dbf4p is displaced from subnuclear foci by replication fork movement in vitro}

The data presented above, and the reversibility of the Gal-DBF4 arrest (Fig. 3C), show that the ORC-dependent association of Dbf4p with chromatin is not regulated like that of Cdc6p or MCMs. However, we do observe a gradual loss of Dbf4p from the chromatin pellet during $\mathrm{S}$ phase in vivo (Fig. 7A,C). This is confirmed by an absence of immunoreactive Dbf4p foci in late $\mathrm{G}_{2}$ - and M-phase cells (Fig. 4A). To test whether this is due to the displacement of Dbf4p during DNA replication, we have followed the fate of epitope-tagged Dbf4p by confocal microscopy and chromatin-binding assays during initiation and subsequent elongation steps in vitro. Wild-type $\mathrm{G}_{1}$ phase nuclei expressing Dbf4-Myc (GA-850), were isolated and incubated in a wild-type GA-59 S-phase extract. DNA synthesis was monitored by the incorporation of DIG-dUTP and subsequent immunodetection (green signals in Fig. 8A,B), revealing foci that overlap partially with the persistent foci of Orc2p staining (red; for details, see Fig. 8, legend). In nuclei that have not yet incorporated DIG-dUTP, we see clear Dbf4p foci (Fig. $8 \mathrm{~B})$. However, as nuclei synthesize increasing amounts of DNA, Dbf4p staining is lost (the parallel detection of newly synthesized DNA and Dbf4p are superimposed in the color panel of Fig. 8B). This series of images represents nuclei at different stages of replication in vitro, demonstrating the progressive loss of the punctate Dbf4p pattern (red), as genomic DNA replication proceeds (DIG-dUTP, green).

To confirm that Dbf4p is released from the replicating nuclei and not simply masked, we have fractionated the nuclei by Triton X-100 extraction either before or after replication in the $S$-phase nuclear extract. As shown above, Dbf4p is present in the wild-type $G_{1}$-phase nuclei prior to replication, and a significant fraction is tightly 
associated with the chromatin pellet (Fig. 8C, labeled $G_{1} n, S$, and $P$ ). When the same fractions are probed for Rpa2p, we find Rpa2p entirely soluble, because the initiation of DNA replication has not yet occurred (Adachi and Laemmli 1994; Pasero et al. 1997; Tanaka and Nasmyth 1998). After a 90-min replication reaction in an S-phase extract, the Triton extraction was repeated, and both pellet and soluble fractions were probed for Dbf $4 \mathrm{p}$ and Rpa2p. Now only a trace of Dbf4p is recovered from either fraction, although the full complement of Rpa2p is present, again primarily in the supernatant (Fig. 8C, labeled -aph). The small fraction of insoluble Rpa2p probably represents the fraction engaged at replication forks, because it is not present when aphidicolin is added (Fig. $8 \mathrm{C}$, cf. -aph and +aph, P). The apparent release or degradation of Dbf4p might either reflect nonspecific proteolysis, the action of the $\mathrm{Clb} / \mathrm{Cdc} 28$ kinase in the extract, or a specific displacement due to the act of replication. When the identical incubation is performed in the presence of aphidicolin, which blocks DNA polymerase but not Cdc28p activity, Dbf4p remains associated with the insoluble nuclear fraction and is largely resistant to degradation (Fig. 8C, +aph, S, and P). The fact that the soluble fraction of Dbf $4 \mathrm{p}$ is degraded in the presence of aphidicolin, whereas the insoluble fraction remains bound and stable, suggests that one of the functions of Dbf4p's association with origin complexes, may be to stabilize this highly labile protein. Although we have not monitored the turnover of Dbf $4 \mathrm{p}$ in intact cells, our in vitro results suggest that active DNA synthesis, rather than active $\mathrm{Clb} / \mathrm{Cdc} 28$ kinase, provokes Dbf4p release from chromatin and enhances its instability.

\section{Discussion}

Cell fusion experiments performed nearly 30 years ago showed that S-phase cytosol provides a diffusible substance that can activate DNA replication in $G_{1}$-phase, but not in $G_{2}$-phase nuclei (Rao and Johnson 1970). This led to two proposals; first, that nuclei can assume at least two states, one in which they are competent to initiate DNA replication and another in which they are not, and second, that a trans-acting, S-phase promoting factor triggers initiation. Although these phenomena could be reconstituted subsequently in replication assays based on Xenopus egg extracts (for review, see Coverley and Laskey 1994; Blow 1996), the identification of the genes and proteins that participate in these events was primarily achieved through the genetic analysis of the $G_{1} / S$ transition in yeast. The components of the pre-RC (ORC, Cdc6p, MCMs, and Cdc45p) were identified and demonstrated genetically to be essential for the initiation of DNA synthesis in yeast. Moreover, mutations in two universally conserved Ser/Thr kinases, Cdc28p and $\mathrm{Cdc} 7 \mathrm{p}$, and their unstable regulatory subunits, arrest or delay passage from $G_{1}$ to $S$ phase (Hartwell et al. 1974; Schwob and Nasmyth 1996; Jallepalli and Kelly 1997). Recently it was shown that inactivation of CDC7 in mid-S phase also impairs initiation at late-firing origins, suggesting that this kinase does not only act at the $G_{1} / S$ transition (Bousset and Diffley 1998; Donaldson et al. 1998a). To explain this observation it was proposed that the Dbf4/Cdc7 kinase acts locally at origins to promote initiation. In this paper we confirm with an in vitro replication assay that the mode of action of Dbf4/Cdc7 kinase is distinctly different from that of $\mathrm{Clb} / \mathrm{Cdc} 28$, which behaves as a diffusible SPF. More importantly, we have confirmed biochemically that Dbf4p, the Cdc7p regulatory subunit, associates with prereplicative chromatin in an ORC-dependent manner. Its binding, which peaks in late $G_{1}$ phase, is nonetheless independent of Cdc6 and MCM complex loading. Finally, we show that the presence of Dbf4p in $G_{1}$-phase nuclei correlates with the potential of these templates for the initiation of DNA synthesis in vitro.

\section{S- or M-phase cyclin/Cdk1 complexes have SPF activity}

Using extracts and template nuclei from mutant yeast strains, we find that either an S-phase or mitotic B-type cyclin/Cdc28 complex, or its vertebrate equivalent, is necessary to stimulate semiconservative DNA replication in $G_{1}$-phase nuclei in vitro. The addition of kinase alone is sufficient to stimulate replication slightly, although another component of the nuclear extract is limiting for maximal replication efficiency (Fig. 1). Our results from in vitro replication are fully consistent with the timing of Clb5p and Clb6p expression and genetic evidence implicating the Clb5,6/Cdc28 kinase in the promotion of replication in vivo (Schwob and Nasmyth 1993 1996; Donaldson et al. 1998b). However, it appears that yeast is rather permissive as to the nature of the $\mathrm{Cdk}$ that can function to initiate DNA replication. In a $G_{1}$ phase extract with high Siclp levels, we find that purified Xenopus CycB/Cdc2 kinase stimulates replication more efficiently than the purified Clb5/Cdc28 kinase (data not shown). This may either indicate a need for both the Clb5 and Clb6/Cdc28 complexes (Donaldson et al. 1998b), or reflect inhibition of the exogenously added Clb5/Cdc28 by the high levels of Siclp. Although the synthesis of Dbf4p also peaks in late $G_{1}$ and early $S$ phase, the presence of active Dbf4/Cdc7 kinase is not required in trans to activate replication in wild-type $\mathrm{G}_{1}$ phase nuclei. Dbf4/Cdc7 is therefore not, formally speaking, a component of SPF.

\section{Dbf4p renders $G_{1}$-phase nuclei competent for activation by $\mathrm{Clb} / \mathrm{Cdc} 28$}

Unlike Cdc7p, which maintains a constant level through the cell cycle, Dbf4p is a highly unstable protein, particularly when cells are blocked by an $\alpha$-factor arrest in early $G_{1}$ (Fig. 3). Using nuclei from a synchronized culture in which we can shut off DBF4 expression, we show that the competence of a late $G_{1}$-phase nucleus to support DNA replication in vitro correlates with the presence of this factor. This is true even when a wild-type $S$-phase extract is added to promote replication. In sup- 
port of this conclusion, we show that the conditional inactivation of either Cdc7p or Dbf4p compromises the replicative ability of $\mathrm{G}_{1}$-phase templates, whereas $c d c 28$ deficient $G_{1}$-phase nuclei replicate efficiently in Cdk1containing extracts.

A one-hybrid assay indicated that Dbf4p can interact with a complex that recognizes the ARS consensus (Dowell et al. 1994), and suggested that at least part of the regulatory function of Dbf $4 \mathrm{p}$ might be to target $\mathrm{Cdc} 7 \mathrm{p}$ to origins. Consistent with this hypothesis, immunolocalization of Dbf4p reveals ORC-like foci in late $G_{1}$ and early $S$ phase, and this punctate distribution is compromised in orc2-1 mutant strains. Using techniques optimized by the Diffley and Stillman laboratories (Donovan et al. 1997; Liang and Stillman 1997), we show that a subpopulation of Dbf4p copurifies with Orc2p in an insoluble nuclear fraction and furthermore, like ORC, resists solubilization by DNase I digestion. Importantly, the association of Dbf4p with the chromatin fraction in late $G_{1}$ requires an intact ORC complex, but not Cdc6p or MCM-bound proteins. Although we cannot rule out that a subfraction of Dbf $4 \mathrm{p}$ can bind the assembled MCM complex, our data clearly define a Cdc6/MCM-independent association that requires intact ORC.

Two pathways dependent on unstable proteins, prepare origins for initiation

It remains an open question as to what are the minimal components required to form a replication-competent origin complex. Clearly, the association of the MCM complex with chromatin and the pre-RC requires the presence of both ORC and Cdc6p (Diffley et al. 1994; Carpenter et al. 1996; Cocker et al. 1996; Coleman et al. 1996). Cdc6p is a highly labile protein, which has to be synthesized in late $G_{1}$ following an $\alpha$-factor block or other events that deplete Cdc6p from the cell. Its ability to load MCM proteins is inhibited by high $\mathrm{Clb} / \mathrm{Cdc} 28$ kinase activity (Piatti et al. 1995, 1996). We propose that association of Dbf4p with chromatin and its potential targeting of Cdc $7 p$ to the pre-RC defines a second pathway necessary for creation of an initiation competent state at origins in $\mathrm{G}_{1}$ (see Fig. 9). In contrast to MCMs, Dbf4p recruitment is clearly independent of Cdc6p, and can occur either in the absence or presence of $\mathrm{Clb} / \mathrm{Cdc} 28$ activity. Like Cdc6p, Dbf4p is highly labile, and is depleted in stationary phase and pheromone-blocked cells. Unlike Cdc6p, however, part of Dbf4p persists in the insoluble nuclear fraction throughout much of $\mathrm{S}$ phase. We propose that two steps are required to form an initiation-competent nucleus: Cdc7p loading through Dbf4p and MCM loading through Cdc6p. Both pathways converge on the MCM complex: The ORC-Cdc6p-MCM pathway assembles MCMs at origins, and the ORCDbf4p pathway is likely to target the Cdc $7 p$ kinase to its critical target, Mcm2p (Lei et al. 1997). This model provides a mechanism to restrict Dbf4/Cdc7 kinase action to those MCMs assembled at origins.

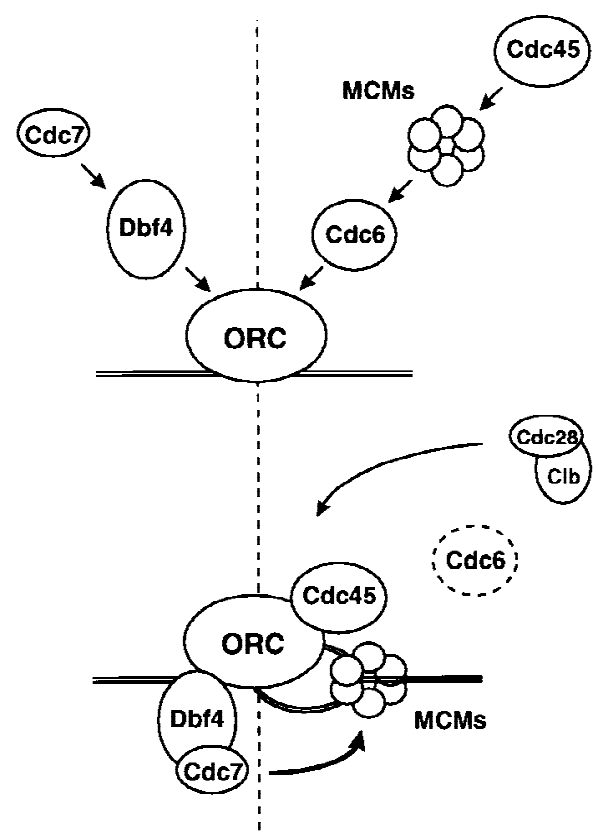

Figure 9. A scheme of two pathways that converge to create initiation-competent origins in yeast nuclei. The binding of MCMs and Cdc45p require the association of Cdc6p with ORC. Cdc6p and MCM binding is inhibited by high Cdk activity, whereas the binding of Cdc45p requires Cdk activity. We propose that the targeting of $\mathrm{Cdc} 7 \mathrm{p}$ to the origin is mediated by Dbf $4 p$ in a manner independent of the activity state of Cdc28 kinase (the dashed line separates Cdk-independent steps from those regulated by Cdk-1). These two pathways converge, because the MCM proteins are physiological targets of Dbf4/Cdc7 and the two complexes interact (bottom; Lei et al. 1997). The activation of $\mathrm{Clb} 5 / \mathrm{Cdc} 28$ as SPF, provokes the binding of Cdc45p, and the degradation or release of Cdc6p. Together the two kinase complexes promote initiation of DNA replication. The formation of initiation-competent origins thus depends on two unstable, factors that show cell cycle-regulated expression, Cdc6p and Dbf4p.

\section{Is the origin-targeting function of Dbf $4 p$ essential?}

Previous studies have shown that deletion of the Dbf $4 \mathrm{p}$ amino terminus renders the protein nonfunctional (Dowell et al. 1994). This deletion removed not only the ARS-targeting domain, but also the only NLS in the protein, thus its inactivity may have reflected the lack of nuclear localization. In a preliminary study, we have overexpressed a series of subdomains of the Dbf4p amino terminus, to see if we could saturate Dbf4p-binding sites at origins. Constructs encoding the full origin-targeting domain cause cell growth arrest when induced, although in liquid culture this is manifest only when cells are recovering from stationary phase or from $\alpha$-factor arrest (P. Pasero and B.P. Duncker, data not shown). This shows that overexpression of the Dbf4N-terminus is not lethal per se, and suggests that competition for origin targeting is most successful when the endogenous Dbf $4 p$ levels drop, and the targeting of Cdc $7 \mathrm{p}$ must be achieved de novo.

The best evidence that the targeting of Dbf $4 p$ through 
ORC may be a regulated event, is demonstrated by the release of Dbf4p from the insoluble nuclear fraction in cells arrested in S phase by HU. This displacement is Rad53p dependent, and results in a highly stabilized, soluble form of Dbf4p. Dbf4p also appears to be displaced from chromatin during DNA synthesis in vitro, although in this case the displaced Dbf4p is rapidly degraded. Thus, the Rad53p modification of Dbf4p (Santocanale and Diffley 1998; J.F. Diffley, pers. comm.) may serve to stabilize the released factor, whereas release of Dbf $4 p$ during a normal $S$ phase may serve to deplete the nuclear pool of Dbf4p to prevent reformation of an active pre-RC. Because the amount of active Cdc7 kinase appears to be regulated primarily through the level of its labile Dbf4p cofactor, a targeting and stabilization of the complex by its association with origins may be essential for achieving a critical concentration of the kinase at its essential sites of action. Such a mechanism is particularly relevant in view of the low abundance and relatively low affinity shown by Cdc7p for its substrates in vitro (Jackson et al. 1993; Dixon and Campbell 1997). Future studies will address the critical question of how Dbf4p synthesis and degradation are controlled, because we predict that these will be closely linked to proper cell cycle progression and recovery from a resting or $\mathrm{G}_{0}$ state.

\section{Materials and methods}

\section{Yeast strains and synchronization}

The strains used in this study are listed in Table 1. All are in the same genetic background, and were backcrossed to W303, except GA-59, GA-85, and GA-161. We have seen no indication that the nuclear replication assay is background dependent. Synchronization of wild-type cells (GA-59; GA-850) in $\mathrm{G}_{1}$ was performed with $\alpha$-factor, which arrests MATa cells prior to Start (Hartwell et al. 1974). The time and amount of pheromone used (generally one generation time or less) are optimized for each strain and recovery after $\mathrm{G}_{1}$ is monitored by FACS analysis. For standard $\mathrm{G}_{1}$-phase nuclei, cultures are arrested with $\alpha$-factor and are subsequently spheroplasted $15 \mathrm{~min}$ in YPD/Sorbitol in the absence of pheromone. Cells progress through Start, but not into $S$ phase, as monitored by an absence of initiation in the endogenous $2 \mu \mathrm{m}$ or other ARS plasmids (Pasero et al. 1997), by the lack of $\mathrm{Clb} / \mathrm{Cdc} 28$ activity (as judged by $\mathrm{H} 1$ kinase assays; e.g., Fig 3), absence of RPA in the chromatin fraction (as detected by immunoblotting; e.g., Fig. 8), and by the presence of Cdc6p, which is released and degraded in S-phase nuclei (data not shown). As a precaution against premature initiation in $\mathrm{G}_{1}$ phase template nuclei, we use a clb5 clb6 strain (GA-769), which enters $S$ phase with a 30-min delay (Schwob and Nasmyth 1993). Where indicated, GA-719 (cln1 $c \ln 2 \quad c \ln 3$ GAL$C L N 3$ ) was used to arrest cells in $\mathrm{G}_{1}$ by shifting to glucose medium. Arrest at the $G_{1} / S$ transition is achieved by galactose induction of a nondegradable form of Siclp in GA-980 cells following $\alpha$-factor block. S-phase or M-phase arrests were obtained by adding, respectively, $200 \mathrm{mM} \mathrm{HU}$ or $20 \mu \mathrm{g} / \mathrm{ml}$ nocodazole in $1 \%$ DMSO to the culture for one generation time. Where indicated, the culture is first synchronized with $\alpha$-factor and then released into medium containing the drug. To prepare $\mathrm{G}_{1}, \mathrm{~S}$ phase or M-phase extracts or nuclei from $c d c 4-1$ (GA-851), cdc7-1 (GA-85), or cdc16-1 (GA-161) mutants, exponential cultures were shifted for $4 \mathrm{hr}$ to the restrictive temperature. Fi- nally, $\mathrm{G}_{1}$-phase extracts and nuclei were prepared from $c d c 28-4$ (GA-112), dbf4 (dna52-1; GA-849), and cdc7-1 (GA-366) cells at permissive temperature directly following $\alpha$-factor arrest, whereas for S-phase extracts, cells were released into YPD until $50 \%$ had small buds. Media are described in Rose et al. (1990).

\section{Spheroplasting of yeast cells and preparation of nuclei and nuclear extracts}

Spheroplasting is performed in YPD/Sorbitol (Pasero et al. 1997) with recombinant $O$. xanthineolytica $\beta-1,3$ glucanase (lyticase) purified from an Escherichia coli strain that overexpresses the gene under the control of the lacUV5 promoter (Shen et al. 1991; Braguglia et al. 1998). Cells are carefully resuspended in YPD/ $1.1 \mathrm{M}$ sorbitol (10 ml/gram) with $40 \mathrm{U} / \mathrm{ml}$ of lyticase and $0.2 \mathrm{mg} / \mathrm{ml}$ Zymolyase 20T (Seikagaku Corp., Japan), and incubated at $30^{\circ} \mathrm{C}$ or $23^{\circ} \mathrm{C}$ until spheroplasts appear round and refractile. For the preparation of nuclear extracts, crude nuclei are isolated and nuclear proteins extracted by $0.9 \mathrm{M}\left(\mathrm{NH}_{4}\right)_{2} \mathrm{SO}_{4}$ as described previously (Pasero et al. 1997, 1999; Braguglia et al. 1998). This same preparation of crude nuclei is used as template for the replication assay.

\section{Replication assay}

In a standard reaction, $10^{7} \mathrm{G}_{1}$-phase nuclei (corresponding to $100 \mathrm{ng}$ of genomic DNA) are incubated in the reaction mixture at either $23^{\circ} \mathrm{C}$ or $35^{\circ} \mathrm{C}$, as described previously (Pasero et al. 1997), but in the presence of $30 \mu \mathrm{Ci}$ of $\left[\alpha-{ }^{32} \mathrm{P}\right] \mathrm{dCTP}$ and $20 \mathrm{~mm}$ dCTP. For density substitution experiments, dTTP is replaced with $200 \mu \mathrm{M}$ BrdUTP. The reactions are stopped by the addition of $25 \mu \mathrm{l}$ of $10 \mathrm{~mm}$ Tris- $\mathrm{HCl}$ (pH 7.0), 0.1\% SDS, 5 mm EDTA, 100 $\mu \mathrm{g} / \mathrm{ml}$ proteinase $\mathrm{K}$. After $1 \mathrm{hr}$ at $37^{\circ} \mathrm{C}$, the genomic DNA is sheared by sonication into fragments of $2-5 \mathrm{~kb}$ and the free label is eliminated with Qiaquick columns (Qiagen). For immunofluorescence experiments, dTTP is replaced with $20 \mu \mathrm{M}$ digoxigenin-11-dUTP (Boehringer Mannheim) and $\left[\alpha-{ }^{32} \mathrm{P}\right] \mathrm{dCTP}$ is omitted. The reaction is stopped by the addition of $4 \%$ paraformaldehyde. Where indicated, $0.5 \mathrm{mg} / \mathrm{ml}$ aphidicolin is added to inhibit replication polymerases.

\section{Cesium chloride density gradient centrifugation}

After the replication reaction and removal of free label, genomic DNA is mixed with a CsCl solution to a final density of 1.7176 grams $/ \mathrm{ml}$ at $25^{\circ} \mathrm{C}(\eta=1.4010)$. The gradients are generated at $36,000 \mathrm{rpm}$ in a fixed-angle T1270 rotor (Sorvall) for $40 \mathrm{hr}$ at $20^{\circ} \mathrm{C}$. Fractions of $250-300 \mu \mathrm{l}$ are collected from the bottom of the gradient with a capillary pipette, counted in a Packard liquid scintillation counter and the refractive index of every second fraction is read. The gradients typically span densities from $1.6742 \mathrm{grams} / \mathrm{ml}(\eta=1.3970)$ to $1.7936(\eta=1.4080)$. HL DNA is usually recovered at $\eta$ values between 1.4035 and 1.4040 , and the L-L peak is between 1.4000 and 1.4010. Quantitation of semiconservative replication was done by integrating the peak of HL DNA and conversion into pmoles of DNA synthesized is performed on the basis of calculation of the specific activity of the radioactive nucleotide and the label incorporated. As discussed in Braguglia et al. (1998), because yeast DNA polymerases incorporate dTTP in vitro fivefold more efficienctly than BrdUTP, the maximal incorporation may be somewhat higher than determined by these experimental conditions.

\section{Immunofluorescence and confocal microscopy}

Following the replication assay in the presence of DIG-dUTP (Boehringer Mannheim), yeast nuclei are fixed for $1 \mathrm{hr}$ at $4^{\circ} \mathrm{C}$ 
Table 1. Strains used in this study

\begin{tabular}{|c|c|}
\hline GA-59 & MATa, leu2, trp1, ura3-52, gal2, prb1-1122, prc1-407, pep4::URA3 \\
\hline GA-85 & $\begin{array}{l}\text { MATa, bar1, his6, leu2-2,-112, trp1-289, ura3-52, cdc7-1 (formerly RM14-3A from B. Brewer, University of } \\
\text { Washington, Seattle) }\end{array}$ \\
\hline GA-112 & $\begin{array}{l}\text { MATa, ade2-11, can1-100, his3-11,-15, leu2-3,-112, trp1-1, ura3, GAL, psi', pep4::URA3, cdc28-4 (formerly K1719 } \\
\text { from K. Nasmyth) }\end{array}$ \\
\hline GA-161 & MATa, his7, ura1, cdc16-1 (L. Hartwell, FHCI, Seattle, WA) \\
\hline GA-366 & $\begin{array}{l}\text { MATa, ade2-1, ade3, can1-100, his3-11,-15, leu2-3,-112, trp1-1, ura3, GAL, psi' , cdc7-1 (formerly K2032 from K. } \\
\text { Nasmyth) }\end{array}$ \\
\hline GA-453 & $\begin{array}{l}\text { MATa, ade2-1, can1-100, his3-11, leu2-3,-112, trp1-1, GAL, psi , ura3::ADH-HA-CLB5/URA3 (formerly K3819 } \\
\text { from K. Nasmyth) }\end{array}$ \\
\hline GA-719 & 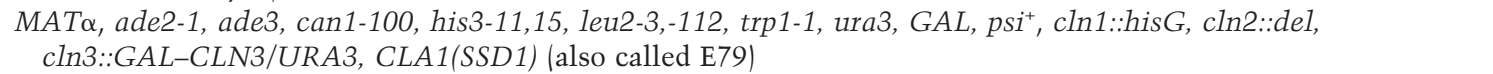 \\
\hline GA-769 & $\begin{array}{l}\text { MATa, ade2-11, can1-100, his3-11,-15, leu2-3,-112, trp1-1, ura3, GAL, psi , clb5::URA3, clb6::LEU2 (also called } \\
\text { E145) }\end{array}$ \\
\hline GA-849 & MATa, can1-11, ura3-52, dna52-1 (dbf4). (also called E458) \\
\hline GA-850 & $\begin{array}{l}\text { MATa, ade2-1, can1-100, his3-11,-15, leu2-3,-112, trp1-1, ura3, GAL, psi , dbf4::DBF4-Myc18/LEU2 (formerly } \\
\text { K6388 from K. Nasmyth) }\end{array}$ \\
\hline GA-851 & MAT $\alpha$, ade2-1, can1-100, his3-11,-15, leu2-3,-112, trp1-1, ura3, GAL, psi ${ }^{+}$, cdc4-1 (also called E197) \\
\hline GA-893 & $\begin{array}{l}\text { MATa, ade2-1, can1-100, his3-11,-15, leu2-3,-112, trp1-1, ura3, GAL, psi', orc2::ORC2-Myc9/LEU2 (formerly } \\
\text { K6447 from K. Nasmyth) }\end{array}$ \\
\hline GA-896 & $\begin{array}{l}\text { MATa, ade2-1, can1-100, his3-11,-15, leu2-3,-112, trp1-1, ura3, GAL, dbf4::HIS3, URA3::GAL-DBF4 (also called } \\
\text { E633) }\end{array}$ \\
\hline GA-980 & $\begin{array}{l}\text { MATa, ade2-1, can1-100, his3-11,-15, leu2-3,-112, trp1-1, GAL, psi', GAL1-SICT5V,T33A, S76A, HA1::URA3, } \\
\text { dbf4::DBF4-myc18/LEU2 (also called E623) }\end{array}$ \\
\hline GA-1026 & MATa, DBF4-myc18/LEU2, cdc6-1 (derived from GA-850) \\
\hline GA-1027 & MATa, DBF4-myc18/LEU2, orc2-1 (derived from GA-850) \\
\hline GA-1123 & GA-850 × GA-1124 \\
\hline GA-1124 & MAT $\alpha$, ade2-1, can1-100, his3-11,-15, leu2-3,112, trp1-1, ura3, orc1::ORC1-HA3/URA3 \\
\hline GA-1212 & $M A T \alpha, D B F 4-m y c 18 / L E U 2$, mec2-1 (derived from GA-850) \\
\hline GA-1213 & $\begin{array}{l}\text { MATa, leu2, cdc6::hisG DBF4-myc18/LEU2, cdc15, ura3::URA3 6ALubiCDC6 (derived from GA-850 and K5032 } \\
\text { from S. Piatti, University of Milan, Italy) }\end{array}$ \\
\hline
\end{tabular}

with $4 \%$ paraformaldehyde, are spotted on a microscope slide and processed for immunodetection as described elsewhere (Gotta et al. 1996). FITC-coupled anti-DIG F(ab) fragments or a monoclonal antibody directed against DIG are used to detect DIG-dUTP incorporation as described in Braguglia et al. (1998). Genomic DNA is stained with ethidium bromide. Confocal microscopy is performed on a Zeiss Axiovert 100 microscope (Zeiss Laser Scanning Microscope 410) with a 63× Plan-Apochromat objective (1.4 oil). Immunofluorescence of nuclear proteins in intact cells was performed as described (Gotta et al. 1996), except that cells were fixed prior to spheroplasting by adding $4 \%$ paraformaldehyde to the culture medium.

\section{Chromatin fractionation assays}

Chromatin association assays are performed as described previously (Donovan et al. 1997; Liang and Stillman 1997), with the following modifications. After spheroplasting, cells are washed once in $20 \mathrm{ml}$ of YPD/ $1.1 \mathrm{M}$ Sorbitol, $0.5 \mathrm{~mm}$ PMSF and three times in $0.25 \times \mathrm{A}$ buffer $(20 \mathrm{~mm}$ Tris- $\mathrm{HCl}$ at $\mathrm{pH} 7.4,20 \mathrm{~mm} \mathrm{KCl}$, 2 mM EDTA-KOH, $0.05 \mathrm{~mm}$ spermine, $0.125 \mathrm{~mm}$ spermidine), supplemented with $1 \mathrm{~m}$ sorbitol, $1 \%$ thiodiglycol, $1 \%$ trasylol, and $0.5 \mathrm{~mm}$ PMSF. The pellet of spheroplasts $\left(\sim 4.10^{8}\right.$ cells $)$ is then resuspended in $1 \mathrm{ml}$ of the same buffer on ice, but containing $0.4 \mathrm{M}$ sorbitol $1 \%$ Triton $\mathrm{X}-100,300 \mu \mathrm{g} / \mathrm{ml}$ benzamidine, $1 \mu \mathrm{g} / \mathrm{ml}$ pepstatin A, $2 \mu \mathrm{g} / \mathrm{ml}$ antipain, $0.5 \mu \mathrm{g} / \mathrm{ml}$ leupeptin, $100 \mu \mathrm{g} / \mathrm{ml} \mathrm{TPCK}$, and $50 \mu \mathrm{g} / \mathrm{ml}$ TLCK. Lysis is monitored by optical microscopy and should be completed within $2 \mathrm{~min}$. The insoluble nuclear fraction is recovered by centrifugation in an Eppendorf centrifuge for $15 \mathrm{~min}$ at $13,500 \mathrm{rpm}$ at $4^{\circ} \mathrm{C}$ and, unless otherwise stated, is resuspended in one-tenth of the ini- tial volume lysis buffer without Triton X-100. DNase I digestion of the insoluble nuclear pellet was performed for $20 \mathrm{~min}$ on ice with $50 \mu \mathrm{g} / \mathrm{ml}$ DNase I and $5 \mathrm{mM} \mathrm{MgCl}_{2}$. The residual scaffold fraction is recovered by centrifugation in an Eppendorf centrifuge for $10 \mathrm{~min}$ at $13500 \mathrm{rpm}$ at $4^{\circ} \mathrm{C}$. Total protein concentration was determined for all fractions by a Bradford assay. Fractionation of nuclei is performed as for spheroplasts.

Western blots were performed by luminescence detection (ECL, Amersham) and multiple exposures of films were scanned and quantitated with the Aida 2.0 software (Raytest). Rabbit anti-Cdc6p was raised against a GST-Cdc6p fusion protein. Other antibodies used are mAb 9E10 (anti-Myc), mAb 12CA5 (anti-HA), mAb TAT1 (anti-tubulin, gift of K. Gull, University of Manchester, UK), mAb 414 (Berkeley Antibodies, CA), and the immune sera, anti-Orc2p (JAb12, gift of J. Diffley, ICRF, South Mimmsa, UK), anti-Mcm2p (YN-19, Santa Cruz Antibodies, CA), anti-Rpa2p (gift of S. Brill, UMDNJ, Nutley, NJ), antip55 ${ }^{\text {RNase }}$ (Karwan et al. 1990, gift of R. Karwan), and anti-Swi6p (gift of K. Nasmyth, IMP, Vienna, Austria).

\section{Kinase assays}

Kinase activity was monitored with histone $\mathrm{H} 1$ according to established protocols (Moreno et al. 1989; Duncker et al. 1999). Label incorporation into H1 was quantified on a Molecular Dynamics PhosphorImager and was standardized to the amount of histone H1 recovered. Partially purified Xenopus Cyclin B/Cdc2 expressed in Sf9 cells was a gift of U.K. Laemmli, P. Grandi, and P. Descombes (University of Geneva, Switzerland), purified recombinant Clb5/Cdc28 was a gift of $\mathrm{M}$. Weinreich (Duncker et al. 1999). Activity is expressed in arbitrary units, on 
the basis of a standard curve of histone $\mathrm{H} 1$ phosphorylation. 1 unit is equivalent to the activity in $20 \mu \mathrm{g}$ of the GA-161 mitotic nuclear extract (Duncker et al. 1999).

\section{Acknowledgments}

We thank B. Brewer, K. Nasmyth, J. Li, S. Piatti, and L. Hartwell for yeast strains, K. Gull for anti-tubulin, C. Mann for antiCdc7p, K. Nasmyth for anti-Swi6p, S. Brill for anti-Rpa2p, J. Diffley for anti-Orc2p, R. Nougarède for setting up conditions for Gal-Dbf4 depletion, and T. Laroche for help with immunofluorescence. Critical reading of the manuscript by C. Frei, V. Simanis, and M. Cockell is gratefully acknowledged. P.P. thanks Association pour le Recherche sur le Cancer (ARC), European Molecular Biology Organization (EMBO), and the Roche Foundation for fellowships. B.P.D. is a research fellow of the National Cancer Institute of Canada supported by funds provided by the Terry Fox Run. Research in the Gasser laboratory is funded by the Swiss National Science Foundation, Human Frontiers Science Program and the Swiss Cancer League.

The publication costs of this article were defrayed in part by payment of page charges. This article must therefore be hereby marked 'advertisement' in accordance with 18 USC section 1734 solely to indicate this fact.

\section{References}

Adachi, Y. and U.K. Laemmli. 1994. Study of the cell cycledependent assembly of the DNA pre-replication centres in Xenopus egg extracts. EMBO J. 13: 4153-4164.

Aparicio, O. M., D.M. Weinstein, and S.P. Bell. 1997. Components and dynamics of DNA replication complexes in S. cerevisiae: Redistribution of MCM proteins and Cdc45p during S phase. Cell 91: 59-69.

Bahman, M., V. Buck, A. White, and J. Rosamond. 1988. Characterisation of the CDC7 gene product of Saccharomyces cerevisiae as a protein kinase needed for the initiation of mitotic DNA synthesis. Biochim. Biophys. Acta 951: 335343.

Blow, J.J. 1996. Chromosome replication in Xenopus egg extracts. In Eukaryotic DNA replication (ed. J.J. Blow), pp. 143 165. IRL Press, Oxford, UK.

Bousset, K. and J.F. Diffley. 1998. The Cdc7 protein kinase is required for origin firing during $\mathrm{S}$ phase. Genes \& Dev. 12: 480-490.

Braguglia, D., P. Heun, P. Pasero, B.P. Duncker, and S.M. Gasser. 1998. Semi-conservative replication in yeast nuclear extracts requires Dna2 helicase and supercoiled template. $J$. Mol. Biol. 281: 631-649.

Brewer, B.J., J.D. Diller, K.L. Friedman, K.M. Kolor, M.K. Raghuraman, and W.L. Fangman. 1993. The topography of chromosome replication in yeast. Cold Spring Harb. Symp. Quant. Biol. 58: 425-434.

Carpenter, P.B., P.R. Mueller, and W.G. Dunphy. 1996. Role for a Xenopus ORC2-related protein in controlling DNA replication. Nature 379: 357-360.

Chapman, J.W. and L.H. Johnston. 1989. The yeast gene, DBF4, essential for entry into $\mathrm{S}$ phase is cell cycle regulated. Exp. Cell. Res. 180: 419-428.

Cocker, J.H., S. Piatti, C. Santocanale, K. Nasmyth, and J.F. Diffley. 1996. An essential role for the Cde6 protein in forming the pre-replicative complexes of budding yeast. Nature 379: $180-182$.

Coleman, T.R., P.B. Carpenter, and W.G. Dunphy. 1996. The
Xenopus Cdc6 protein is essential for the initiation of a single round of DNA replication in cell-free extracts. Cell 87: 53-63.

Coverley, D. and R.A. Laskey. 1994. Regulation of eukaryotic DNA replication. Annu. Rev. Biochem. 63: 745-776.

Diffley, J.F. 1996. Once and only once upon a time: Specifying and regulating origins of DNA replication in eukaryotic cells. Genes \& Dev. 10: 2819-2830.

Diffley, J.F., J.H. Cocker, S.J. Dowell, and A. Rowley. 1994. Two steps in the assembly of complexes at yeast replication origins in vivo. Cell 78: 303-316.

Dixon, W.J. and J.L. Campbell. 1997. Preparation of active Cdc7/Dbf4 kinase from yeast cells. Methods Enzymol. 283: 390-397.

Donaldson, A.D., W.L. Fangman, and B.J. Brewer. 1998a. Cdc7 is required throughout the yeast $\mathrm{S}$ phase to activate replication origins. Genes \& Dev. 12: 491-501.

Donaldson, A.D., M.K. Raghuraman, K.L. Friedman, F.R. Cross, B.J. Brewer, and W.L. Fangman. 1998b. CLB5-dependent activation of late replication origins in S. cerevisiae. Mol. Cell 2: $173-182$.

Donovan, S., J. Harwood, L.S. Drury, and J.F. Diffley. 1997. Cdc6p-dependent loading of Mcm proteins onto pre-replicative chromatin in budding yeast. Proc. Natl. Acad. Sci. 94: 5611-5616.

Dowell, S.J., P. Romanowski, and J.F. Diffley. 1994. Interaction of Dbf4, the Cdc7 protein kinase regulatory subunit, with yeast replication origins in vivo. Science 265: 1243-1246.

Duncker, B.P., P. Pasero, D. Braguglia, P. Heun, M. Weinreich, and S.M. Gasser. 1999. Cyclin B-cdk1 kinase stimulates ORC- and Cdc6-independent steps of semiconservative plasmid replication in yeast nuclear extracts. Mol. Cell. Biol. 19: $1226-1241$.

Dutta, A. and S.P. Bell. 1997. Initiation of DNA replication in eukaryotic cells. Annu. Rev. Cell Dev. Biol. 13: 293-332.

Fox, C.A., S. Loo, A. Dillin, and J. Rine. 1995. The origin recognition complex has essential functions in transcriptional silencing and chromosomal replication. Genes \& Dev. 9: 911-924.

Gotta, M., T. Laroche, A. Formenton, L. Maillet, H. Scherthan, and S.M. Gasser. 1996. The clustering of telomeres and colocalization with Rap1, Sir3, and Sir4 proteins in wild-type Saccharomyces cerevisiae. J. Cell Biol. 134: 1349-1363.

Hardy, C.F. 1996. Characterization of an essential Orc2p-associated factor that plays a role in DNA replication. Mol. Cell. Biol. 16: 1832-1841.

Hardy, C.F. and A. Pautz. 1996. A novel role for Cdc5p in DNA replication. Mol. Cell. Biol. 16: 6775-6782.

Hardy, C.F., O. Dryga, S. Seematter, P.M. Pahl, and R.A. Sclafani. 1997. $\mathrm{mcm} 5 / \mathrm{cdc} 46-b o b 1$ bypasses the requirement for the S phase activator Cdc7p. Proc. Natl. Acad. Sci. 94: 31513155.

Hartwell, L.H. 1976. Sequential function of gene products relative to DNA synthesis in the yeast cell cycle. J. Mol. Biol. 104: 803-817.

Hartwell, L.H., J. Culotti, J.R. Pringle, and B.J. Reid. 1974. Genetic control of the cell division cycle in yeast. Science 183: 46-51.

Hennessy, K.M., A. Lee, E. Chen, and D. Botstein. 1991. A group of interacting yeast DNA replication genes. Genes \& Dev. 5: 958-969.

Hereford, L.M. and L.H. Hartwell. 1974. Sequential gene function in the initiation of Saccharomyces cerevisiae DNA synthesis. J. Mol Biol. 84: 445-461.

Hollingsworth, R.E. Jr. and R.A. Sclafani. 1990. DNA metabolism gene $C D C 7$ from yeast encodes a serine (threonine) pro- 
tein kinase. Proc. Nat1. Acad. Sci. 87: 6272-6276.

Hua, X.H. and J. Newport. 1998. Identification of a preinitiation step in DNA replication that is independent of Origin Recognition Complex and Cdc6, but dependent on Cdk2. J. Cell Biol. 140: 271-281.

Jackson, A.L., P.M. Pahl, K. Harrison, J. Rosamond, and R.A. Sclafani. 1993. Cell cycle regulation of the yeast Cdc7 protein kinase by association with the Dbf4 protein. Mol. Cell. Biol. 13: 2899-2908.

Jallepalli, P.V. and T.J. Kelly. 1997. Cyclin-dependent kinase and initiation at eukaryotic origins: A replication switch? Curr. Opin. Cell. Biol. 9: 358-363.

Jiang, W. and T. Hunter. 1997. Identification and characterization of a human protein kinase related to budding yeast Cdc7p. Proc. Natl. Acad. Sci. 94: 14320-14325.

Karwan, R.M., T. Laroche, U. Wintersberger, S.M. Gasser, and M. Binder. 1990. Ribonuclease H(70) is a component of the yeast nuclear scaffold. J. Cell Sci. 96: 451-459.

Kitada, K., L.H. Johnston, T. Sugino, and A. Sugino. 1992. Temperature-sensitive cdc7 mutations of Saccharomyces cerevisiae are suppressed by the DBF4 gene, which is required for the G1/S cell cycle transition. Genetics 131: 21-29.

Krude, T., M. Jackman, J. Pines, and R.A. Laskey. 1997. Cyclin/ Cdk-dependent initiation of DNA replication in a human cell-free system. Cell 88: 109-119.

Lei, M., Y. Kawasaki, M.R. Young, M. Kihara, A. Sugino, and B.K. Tye. 1997. Mcm2 is a target of regulation by Cdc7-Dbf4 during the initiation of DNA synthesis. Genes \& Dev. 11: 3365-3374.

Liang, C. and B. Stillman. 1997. Persistent initiation of DNA replication and chromatin-bound MCM proteins during the cell cycle in cdc6 mutants. Genes \& Dev. 11:3375-3386.

Liang, C., M. Weinreich, and B. Stillman. 1995. ORC and Cdc6p interact and determine the frequency of initiation of DNA replication in the genome. Cell 81: 667-676.

Loo, S., C.A. Fox, J. Rine, R. Kobayashi, B. Stillman, and S. Bell. 1995. The origin recognition complex in silencing, cell cycle progression, and DNA replication. Mol. Biol. Cell. 6: 741756.

Masai, H., T. Miyake, and K. Arai. 1995. hsk1+, a Schizosaccharomyces pombe gene related to Saccharomyces cerevisiae $C d c 7$, is required for chromosomal replication. EMBO $J$. 14: 3094-3104.

Moreno, S., J. Hayles, and P. Nurse. 1989. Regulation of p34cdc2 protein kinase during mitosis. Cell 58: 361-372.

Newlon, C.S. 1997. Putting it all together: Building a prereplicative complex. Cell 91: 717-720.

Pasero, P. and S.M. Gasser. 1998. New systems for replicating DNA in vitro. Curr. Opin. Cell Biol. 10: 304-310.

Pasero, P., D. Braguglia, and S.M. Gasser. 1997. ORC-dependent and origin-specific initiation of DNA replication at defined foci in isolated yeast nuclei. Genes \& Dev. 11: 1504-1518.

Pasero, P., B.P. Duncker, and S.M. Gasser. 1999. In vitro DNA replication in yeast nuclear extracts. Methods, Companion Methods Enzymol. (In press).

Piatti, S., C. Lengauer, and K. Nasmyth. 1995. Cdc6 is an unstable protein whose de novo synthesis in G1 is important for the onset of $S$ phase and for preventing a 'reductional' anaphase in the budding yeast Saccharomyces cerevisiae. EMBO J. 14: 3788-3799.

Piatti, S., T. Bohm, J.H. Cocker, J.F. Diffley, and K. Nasmyth. 1996. Activation of S-phase-promoting CDKs in late $\mathrm{G}_{1}$ defines a 'point of no return' after which Cdc6 synthesis cannot promote DNA replication in yeast. Genes \& Dev. 10: 15161531.

Raghuraman, M.K., B.J. Brewer, and W.L. Fangman. 1997. Cell cycle-dependent establishment of a late replication program. Science 276: 806-809.

Rao, P.N. and R.T. Johnson. 1970. Mammalian cell fusion: Studies on the regulation of DNA synthesis and mitosis. Nature 225: 159-164.

Rose, M.D., F. Winston, and P. Hieter. 1990. Methods in yeast genetics Cold Spring Harbor Laboratory Press, Cold Spring Harbor, NY.

Rout, M.P. and G. Blobel. 1993. Isolation of the yeast nuclear pore complex. J. Cell Biol. 123: 771-783.

Santocanale, C. and J.F. Diffley. 1996. ORC- and Cdc6-dependent complexes at active and inactive chromosomal replication origins in S. cerevisiae. EMBO J. 15: 6671-6619.

. 1998. Mec1- and Rad53-dependent checkpoint controls late-firing origins of DNA replication. Nature 395: 615-618.

Sato, N., K. Arai, and H. Masai. 1997. Human and Xenopus cDNAs encoding budding yeast Cdc7-related kinases: In vitro phosphorylation of MCM subunits by a putative human homologue of Cdc7. EMBO J. 16: 4340-4351.

Schwob, E. and K. Nasmyth. 1993. CLB5 and CLB6, a new pair of B cyclins involved in DNA replication in Saccharomyces cerevisiae. Genes \& Dev. 7: 1160-1175.

- 1996. Cell cycle control of DNA replication in Saccharomyces cerevisiae. In Eukaryotic DNA replication (ed. J.J Blow), pp. 165-197. IRL Press Oxford, UK.

Schwob, E., T. Bohm, M.D. Mendenhall, and K. Nasmyth. 1994. The B-type cyclin kinase inhibitor p40SIC1 controls the G1 to $S$ transition in S. cerevisiae. Cell 79: 233-244.

Sclafani, R.A. and A.L. Jackson. 1994. Cdc7 protein kinase for DNA metabolism comes of age. Mol. Microbiol. 11: 805810.

Sclafani, R.A., M. Patterson, J. Rosamond, and W.L. Fangman. 1988. Differential regulation of the yeast CDC7 gene during mitosis and meiosis. Mol. Cell. Biol. 8: 293-300.

Shen, S.H., P. Chretien, L. Bastien, and S.N. Slilaty. 1991. Primary sequence of the glucanase gene from Oerskovia xanthineolytica. Expression and purification of the enzyme from Escherichia coli. J. Biol.Chem. 266: 1058-1063.

Tanaka T. and K. Nasmyth. 1998. Association of RPA with chromosomal replication origins requires an $\mathrm{Mcm}$ protein, and is regulated by Rad53, and cyclin- and Dbf4-dependent kinases. EMBO J. 17: 5182-5191.

Tanaka, T., D. Knapp, and K. Nasmyth. 1997. Loading of an $\mathrm{Mcm}$ protein onto DNA replication origins is regulated by Cdc6p and CDKs. Cell 90: 649-660.

Verma, R., R.M. Feldman, and R.J. Deshaies. 1997. SIC1 is ubiquitinated in vitro by a pathway that requires $C D C 4, C D C 34$ and cyclin/CDK activities. Mol. Biol. Cell 8: 1427-1437.

Walter, J., L. Sun, and J. Newport. 1998. Regulated chromosomal DNA replication in the absence of a nucleus. Mol. Cell 1: 519-529.

Weinert, T., G.L. Kiser, and L.H. Hartwell. 1994. Mitotic checkpoint genes in budding yeast and the dependence of mitosis on DNA replication and repair. Genes \& Dev. 8: 652-665.

Yan, H., S. Gibson, and B.K. Tye. 1991. Mcm2 and Mcm3, two proteins important for ARS activity, are related in structure and function. Genes \& Dev. 5: 944-957.

Yoon, H.J. and J.L. Campbell. 1991. The CDC7 protein of $S$. cerevisiae is a phosphoprotein that contains protein kinase activity. Proc. Natl. Acad. Sci. 88: 3574-3578.

Yoon, H.J., S. Loo, and J.L. Campbell. 1993. Regulation of $S$ cerevisiae CDC7 function during the cell cycle. Mol. Biol. Cell. 4: 195-208.

Zou, L. and B. Stillman. 1998. Formation of a preinitiation complex by S-phase cyclin CDK-dependent loading of Cdc45p onto chromatin. Science 280: 593-596. 


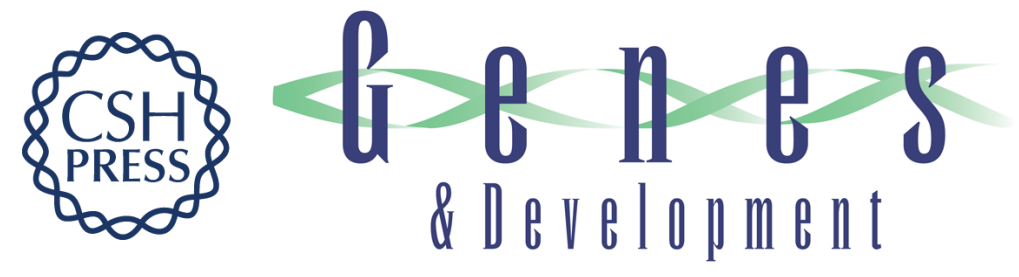

\section{A role for the Cdc7 kinase regulatory subunit Dbf4p in the formation of initiation-competent origins of replication}

Philippe Pasero, Bernard P. Duncker, Etienne Schwob, et al.

Genes Dev. 1999, 13:

References This article cites 68 articles, 38 of which can be accessed free at:

http://genesdev.cshlp.org/content/13/16/2159.full.html\#ref-list-1

License

Email Alerting Receive free email alerts when new articles cite this article - sign up in the box at the top Service right corner of the article or click here.

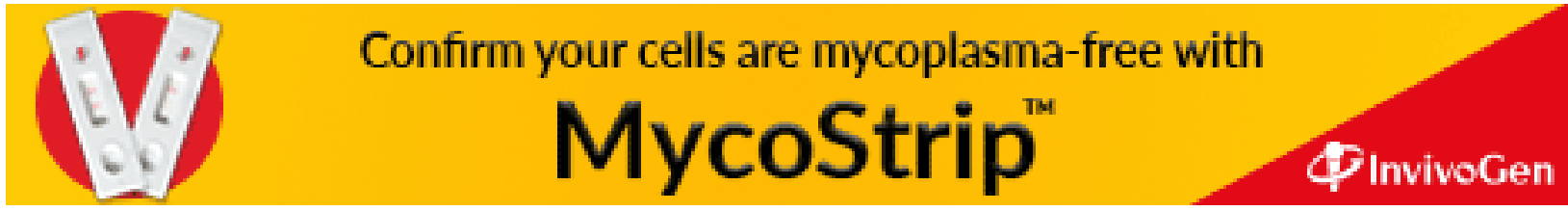

